\title{
TENDÊNCIAS E DIFERENCIAIS NA SAÚDE PERINATAL NO MUNICÍPIO DE FORTALEZA, CEARÁ: 1995 e 2005
}

\author{
ANA VALESKA SIEBRA E SILVA \\ Tese apresentada ao Programa de Pós Graduação em \\ Saúde Pública para obtenção do título de Doutor em \\ Saúde Pública \\ Área de Concentração: Epidemiologia \\ Orientador: Profa.Dra.Sabina Léa Davidson Gotlieb
}

São Paulo

2010 
Tendências e diferenciais na saúde perinatal no município de Fortaleza, Ceará: 1995 e 2005

\section{Ana Valeska Siebra e Silva}

Tese apresentada ao Programa de Pós Graduação em Saúde Pública da Faculdade de Saúde Pública da Universidade de São Paulo para obtenção do título de Doutor em Saúde Pública

Área de Concentração: Epidemiologia

Orientador: Profa.Dra.Sabina Léa Davidson Gotlieb

São Paulo 
Tendências e Diferenciais na Saúde Perinatal no Município de Fortaleza, Ceará: 1995 e 2005. / Ana Valeska Siebra e Silva. São Paulo. 2010.

Tese (Doutorado) - Universidade Estadual do Ceará. Faculdade de São Paulo, Programa de Pós-Graduação em Saúde Pública.

Área de Concentração: Epidemiologia

Orientadora: Sabina Léa Davidson Gotlieb

1.Coeficiente de Mortalidade Perinatal. 2. Mortalidade Neonatal Precoce 3. Muito Baixo Peso ao Nascer 



\section{DEDICATÓRIA ESPECIAL}

Para minhas duas filhas, Ludmila e Lis de Maria, que consolidaram em mim o sentido da maternidade. "... todo o amor que houver nessa vida..."

Aos meus pais, Milton e Zélia pelo apoio, zelo e dedicação. Obrigada por tudo e por acreditarem em mim.

Ao Silveira, eterno namorado, que soube compreender a minha ausência, o meu terno amor. 


\section{AGRADECIMENTOS}

Á Deus, pelo dom precioso da vida.

À minha orientadora, Professora Doutora Sabina Léa Davidson Gotlieb, pelo acolhimento, ensinamentos e incentivo prestados por todo nosso convívio.

Aos Professores Doutores Eurivaldo e Péricles, pelo apoio prestado à turma do DINTER- Ceará durante todo o curso.

À Universidade Estadual do Ceará, pelos esforços em empreender convênio com a Universidade de São Paulo, nos possibilitando o curso de Doutorado.

À Escola de Saúde Pública, pela acolhida e receptividade nesta longa jornada.

Ao Hospital Infantil Albert Sabin: Dr. Walter, Daura, Zélia, Marcília, Luíza. Kleiber, Rosângela, Olaneide , obrigada por tudo!

Ao extremo incentivo, presteza e atenção dispensado ao grupo do DINTER,pelo nosso querido coordenador local Professor Osmar e da nossa querida Neila, a mais competente secretária

À amiga dileta e agora cumadre Rejane:

...diante do amigo sabemos que não estamos sós. E alegria maior não pode existir! Rubem Alves, 1999.

À Nádia, amiga "querida", pelas orientações nas terças à tarde no NEAPE... " como é grande o meu amor por você..."

À amiga Anamaria Cavalcante e Silva, por todas as vezes que me inspirou com suas inquietações constantes em favor da saúde das crianças, pelos ensinamentos, pela amizade enfim por tudo que tive oportunidade de aprender. 
Ao amigo e sempre orientador, Professor Álvaro Madeiro Leite, pelas indispensáveis orientações que cada vez mais nos engrandece e nos permite pensar em uma vida melhor

Á minha amiga e "chefe" Edna Guerra, por todas às vezes que teve que me "liberar" e me "substituir nas minhas ausências.

Val e Cleiton, obrigada por me aturarem... Que paciência!

Ao Daniel (Dan Dan), que todas às vezes me recebeu com seu sorriso largo e acolhedor, sua calma me contagiou...muito obrigada por tudo.

À Liduína, secretária competente, mãe dedicada, valeu por tudo!

Ao meu querido Haroldo, secretário nota 10, pelo cuidado, carinho... obrigada por não se esquecer de mim, mesmo estando ausente.

Às coordenadoras do curso de Enfermagem da UECE, Professoras Bárbara Pereira D'Alencar e llse Maria Tigre de Arruda Leitão, pelo incentivo dado ao longo curso.

Às amigas Daura Porto e Zélia Mota, pela compreensão, pela presteza e por estarem sempre ao meu lado.

Aos professores da USP, da UFC e da UECE que estiveram conosco ao longo desta travessia. Obrigada por tantos ensinamentos.

Fernão sua ajuda e sabedoria foram imprescindíveis e inesquecívies naquele momento da orientação.

Às secretárias Maria do Carmo e Margareth, pela presteza inestimável.

Aos amigos de todas as horas do Ponto das Cópias, em especial ao Romel, Elias e Júnior, sempre me tirando do sufoco. Vocês são demais! 


\section{LISTA DE TABELAS}

Página

41

Tabela 1.Distribuição do número e proporção (\%) dos nascimentos segundo hospital-maternidade em 1995 e 2005. Fortaleza-Ceará.

Tabela 2. Distribuição do número e proporção(\%) das perdas fetais hospitalares segundo peso ao nascer (em gramas) em 1995 e 2005. Fortaleza-Ceará.

Tabela 3. Distribuição do número e proporção(\%)de óbitos neonatais precoceshospitalares segundo peso ao nascer (em gramas) em 1995 e 2005. Fortaleza-Ceará.

Tabela 4. Distribuição do número e proporção(\%) dos 46 nascimentoshospitalares sobreviventes até $07^{0}$ diade vida segundo peso ao nascer (em gramas) em 1995 e 2005. Fortaleza-Ceará.

Tabela 5. Coeficientes de mortalidade hospitalar perinatal (por mil nascimentos) segundo peso ao nascer (em gramas) entre 1995 e 2005 Fortaleza-Ceará.

Tabela 6. Coeficiente de mortalidade fetal (por 1.000 nascimentos) segundo peso ao nascer (em gramas), em 1995 e 2005. FortalezaCeará

Tabela 7.Coeficientes de mortalidade neonatal precoce hospitalar (por 1.000 nascidos vivos)segundo peso ao nascer (em gramas) em 1995 e 2005. Fortaleza-Ceará

Tabela 8. Coeficientes de mortalidade perinatal hospitalar (por 1000 nascimentos), segundo categorias ${ }^{\star}$ de peso ao nascer (em gramas) em 1995 e 2005. Fortaleza-Ceará

Tabela 9. Coeficientes de mortalidade fetal hospitalar (por mil nascimentos) segundo categorias* de peso ao nascer (em gramas) em 1995 e 2005. Fortaleza-Ceará

Tabela 10. Coeficientes de mortalidade neonatal precoce hospitalar (por 1.000 nascidos vivos) segundo categorias* de peso ao nascer (em gramas) em 1995 e 2005. Fortaleza-Ceará

Tabela 11. Proporção de nascidos vivos de muito baixo peso ao 
de mortalidade neonatal precoce hospitalar (por 1.000 nascidos vivos de muito baixo peso) em 1995 e 2005, Fortaleza, Ceará.

Tabela 12. Proporção de nascidos vivos de baixo peso (\%), mortalidade neonatal precoce hospitalar (\%) e coeficiente de mortalidade neonatal precoce hospitalar (por 1.000 nascidos vivos de baixo peso) em 1995 e 2005, Fortaleza, Ceará.

Tabela 13. Nascidos vivos de peso insuficiente ao nascer (\%) e respectivos mortalidade neonatal precoce hospitalar (\%) e coeficiente de mortalidade neonatal precoce hospitalar (por 1.000 nascidos vivos de peso insuficiente), em 1995 e 2005, Fortaleza, Ceará.

Tabela 14. Proporção dos nascidos vivos de peso satisfatório ao nascer (\%) e respectivos mortalidade neonatal precoce hospitalar (\%) e Coeficiente de mortalidade neonatal precoce hospitalar (por 1.000 nascidos vivos de peso satisfatório), em 1995 e 2005, Fortaleza, Ceará.

Tabela 15. Proporção (\%) de cesáreas de acordo com os hospitaismaternidades em 1995 e 2005. Fortaleza-Ceará.

Tabela 16. Coeficientes da mortalidade perinatal segundo a idade materna (por 1000 nascimentos) em 1995 e 2005 em Fortaleza-Ceará. Tabela 17. Coeficientes da mortalidade fetal segundo a idade materna (por 1000 nascimentos ) em 1995 e 2005 em Fortaleza-Ceará.

Tabela 18. Coeficientes de mortalidade neonatal precoce de acordo com idade materna (por 1000 nascimentos) entre 1995 e 2005. Fortaleza-Ceará. 


\section{LISTA DEGRÁFICOS}

Página

Gráfico 1. Proporção (\%) dos nascimentos hospitalares segundo

categoria dos hospitais Fortaleza-Ceará, 1995 e 2005

Gráfico 2. Coeficientes de mortalidade perinatal hospitalar (por 1000

nascimentos) segundo categorias* de peso ao nascer (em gramas) em 1995 e 2005. Fortaleza-Ceará

Gráfico 3. Coeficientes de mortalidade perinatal hospitalar (por 1000 nascimentos) segundo categorias de peso ao nascer, Fortaleza, 1995 e 2005. 
Lista de tabelas

Lista de gráficos

Resumo

Abstract

1.INTRODUÇÃO

1.1.Mortalidade infantil: o cenário mundial 15

$\begin{array}{ll}\text { 1.2.Os determinantes dos óbitos infantis } & 18\end{array}$

1.3.A evolução da mortalidade infantil no Brasil das desigualdades 21

1.5.A mortalidade perinatal e suas repercussões na saúde da mulher grávida e de seu recém nascido

1.6. Fortaleza o cenário do estudo 27

$\begin{array}{ll}\text { 2.Justificativa } & 30\end{array}$

3.Objetivos 31

3.1.Objetivo geral 31

3.2.Objetivo específico 31

4.Metodologia 32

4.1. Tipo de estudo 32

4.2.População 32

4.3.Sobre os dados dos estudos de 1995 e 2005

4.4. Análise dos Resultados 38

4.5. Aspectos Éticos 38

5. Resultados 39

6. Discussão dos Resultados 60

7.Consideração Finais $\quad 80$

8.Referências Bibliográficas

9.Anexos 


\section{RESUMO}

Introdução: $O$ presente estudo trata da evolução da mortalidade perinatal hospitalar do município de Fortaleza-Ceará em dois momentos: 1995 e 2005. O interesse para a realização desta pesquisa parte da relevância dos cuidados oferecidos à mulher grávida e ao recém nascidocomo importante indicador da saúde materno infantil.Objetivos: Avaliar a evolução dos indicadores de saúde perinatal referentes aos nascimentos hospitalares de Fortaleza, Ceará, ocorridos em 1995 e em 2005.Metodologia: Estudo epidemiológico, do tipo ecológico, que estuda a evolução da saúde perinatal em Fortaleza, de 1995 a 2005, a partir da análise dos dados de dois estudos de base hospitalar. Todos os nascimentos foram acompanhados desde o parto até a alta ou óbito em hospital.Fizeram parte da população, todos os nascimentos e respectivos óbitos perinatais ocorridos em hospitais/maternidades públicas e particulares, conveniados com o SUS, no município de Fortaleza, CE, em 1995 e em 2005, disponíveis em dois bancos de dados já existentes.Resultados: Os resultados evidenciaram que nos dez anos (1995-2005) houve melhoria nos indicadores de saúde perinatal em Fortaleza. Os coeficientes de mortalidade perinatal hospitalar, fetal e neonatal precoce tiveram redução de $29 \%, 19,0 \%$ e de $42 \%$ respectivamente. Em crianças com baixo peso ao nascer,observou-se declínio na mortalidade perinatal, fetal e neonatal precoce em todas as categorias. Chama-se atenção para a redução do coeficiente de mortalidade perinatal no grupo de recém nascidos de muito baixo peso $(<1500 \mathrm{~g})$, que passou de 821,1/1000 NV em 1995 para 532,2/1000 NV em 2005, com um declínio de 35,2\%. Quanto ao coeficiente de mortalidade neonatal precoce, a redução foi de 53,8\%, passando de 703,0/1000 NV para 324,7/1000 NV. Foi possível evidenciar mudanças referentes à reorganização da atenção perinatal em Fortaleza, quando se detectou uma maior participação dos hospitais públicos, que realizou um maior número de partos nos dez anos 
em 121\%\%. Em 1995 a proporção de partos foi de 32,4\% e em 2005 de $71,7 \%$. Quanto à idade materna, os coeficientes de mortalidade perinatal, fetal e neonatal precoce nos dez anos tiveram reduções, com ênfase entre os filhos de mães adolescentes (10 a 19 anos). Para este grupo, o coeficiente de mortalidade perinatal obteve declínio de $54,2 \%$ o de mortalidade fetal de $16,2 \%$ e o de mortalidade neonatal precoce de $36,8 \%$.

Conclusões: A mudança nos indicadores da saúde perinatal no município de Fortaleza mostra que houve uma melhora da atenção ao longo dos dez anos, revelando um cenário favorável na atenção prestada à mulher grávida e ao recém nascido na capital. Contudo, sabe-se que aspectos relacionados com o processo de trabalho e a organização da rede, ainda permanecem em níveis inferiores em relação, quando compara-se com outras capitais brasileiras, sendo necessárias medidas governamentais para que estas lacunas sejam remediadas.

Palavras-chaves: mortalidade perinatal, mortalidade neonatal precoce, mortalidade fetal, recém-nascido de muito baixo peso 
ABSTRACT

Introduction: This study deals with the evolution of perinatal mortality hospital in Fortaleza, Ceara on two occasions: 1995 and 2005. The interest for this research part of the relevance of care offered to pregnant women and newborn care as an important indicator of maternal and infant health.Objectives: To evaluate perinatal health indicators relating to hospital births in Fortaleza, occurring in 1995 and 2005.Methodology: Epidemiological study of ecological type, which studies the evolution of perinatal health in Fortaleza, from 1995 to 2005, based on the analysis of data from two hospital-based studies. All births were followed from birth until discharge or death in hospital. The population was composed of all births and perinatal deaths occurred in their hospitals / public hospitals and private contracts with the SUS in the city of Fortaleza, in 1995 and 2005, available in two databases that already exist.Results: The results showed that within ten years (1995-2005) found a reduction in perinatal health indicators in Fortaleza. The hospital perinatal mortality rates, fetal and early neonatal fell by $29 \%, 19.0 \%$ and $42 \%$ respectively. As birth weight were obtained decline in perinatal mortality, fetal and early neonatal in all categories. Attention is drawn to the reduction of perinatal mortality rate in the group of infants with very low birthweight $(<1500 \mathrm{~g})$, now 821.1 / NV in 1000 to 532.2 in 1995 / $1000 \mathrm{NV}$ in 2005 , with a declining $35.2 \%$. As for early neonatal mortality rate, the reduction was $53.8 \%$, from 703.0 / 324.7 for 1000 NV / NV 1000. The results showed changes related to the reorganization of perinatal care in Fortaleza, when it detected a greater involvement of public hospitals, which increased the number of births in the ten years 121\%\%. In 1995 the proportion of births was $32.4 \%$ and $71.7 \%$ in 2005 . As for maternal age, perinatal mortality rates, fetal and early neonatal ten years have had reductions, with emphasis among the children of teenage mothers (10-19 years). For this group, the perinatal mortality rate decline of $84.7 \%$ was 
obtained, the fetal mortality of $46.8 \%$ and early neonatal mortality rate of 88.7\%.Conclusions: The change in perinatal health indicators in Fortaleza shows that there was an improvement of attention over the ten years, revealing a favorable outlook on care provided to pregnant women and newborn in capital.Contudo, it is known that aspects related to the work process and organization of the network, are still inconsistent when it is compared with other Brazilian cities, requiring government measures to these deficiencies are remedied.

Keywords: Perinatal mortality, early neonatal mortality, fetal mortality, newborn very low birth weight 


\section{INTRODUÇÃO}

\subsection{MORTALIDADE INFANTIL: O CENÁRIO MUNDIAL}

Na década de 80, a revolução em favor da sobrevivência infantil nos países em desenvolvimento contribuiu significativamente para a redução dos coeficientes de mortalidade infantil, principalmente, por doenças preveníveis e infecciosas. ${ }^{1}$

Em países ricos, a redução dos óbitos de crianças foi sendo alcançada graças à melhor qualidade de vida proporcionada à população. Entretanto, naquelas nações em processo de desenvolvimento, as injustas desigualdades sociais, as precárias condições de moradia, do saneamento básico, de alimentação, as dificuldades de acesso e a qualidade da assistência oferecida nos serviços de saúde, vêm sendo determinantes importantes das mortes infantis. ${ }^{2}$

Vale mencionar que os avanços conquistados por estes países mais pobres, em favor da sobrevida de suas crianças, foram de grande relevância, visto que já estão disponíveis ações simples, confiáveis e financeiramente acessíveis. O grande desafio mundial, talvez, seja a garantia do acesso destas intervenções às milhares de crianças que ainda não tenham sido favorecidas.

Segundo a UNICEF, a cada dia morrem mais de 26 mil crianças com menos de cinco anos em todo o mundo e a maioria falece por causas evitáveis. Quase todas estas crianças vivem em países em 
desenvolvimento, com precárias condições de vida. Vale ainda enfatizar que $30 \%$ destes óbitos ocorrem no domicílio, no primeiro mês de vida e sem nenhum acesso aos serviços de saúde ou outros recursos capazes de evitálos. ${ }^{1}$

O coeficiente de mortalidade infantil é um indicador sensível das condições de vida oferecidas pelos governos às suas populações. Não só é capaz de medir, indiretamente, as condições de bem estar, políticas, éticas e de saúde em que vivem seus habitantes, mas também a responsabilidade social, o compromisso e a proteção da sociedade pela sua renovação geracional. É uma eloqüente evidência de suas prioridades e de seus valores, além de ser o caminho para a construção de um futuro digno e promissor. $^{1,3}$

Estudo ressalta que os níveis da mortalidade estão diretamente relacionados com o resultado de ações inter-relacionadas de três grupos de fatores: o bem-estar da população, a oferta e o acesso aos serviços públicos de saúde, que causam impacto na melhoria do nível de saúde da comunidade, e as características de cada indivíduo. ${ }^{4}$

A surpreendente evolução histórica do declínio dos coeficientes de mortalidade em todo o mundo ocorreu na década de oitenta, com variações entre as diferentes regiões do mundo. Decresceram em quase $50 \%$, no leste da Ásia e do Pacífico, na Europa Central e Oriental, na América Latina e Caribe e chegaram, em 2006, a 30 mortes de menores de um ano por mil nascidos vivos, nestes países. ${ }^{1}$ 
Reconhece-se que as transformações socioeconômicas associadas à ampliação da rede de água e esgoto sanitário, às novas frentes de trabalho, à melhor renda familiar, à moradia e proteção social, às transformações institucionais relacionadas à criação do acesso aos serviços de saúde, ocasionaram forte impacto sobre os níveis da mortalidade infantil, principalmente nos países em desenvolvimento.

Frente a estes avanços e à magnitude deste problema, o foco atual dos países vem sendo o desenvolvimento de estratégias para alcançar a quarta meta dos Objetivos do Milênio, que visa reduzir em dois terços o coeficiente de mortalidade infantil até 2015 , a partir do ano base de $1990 .^{5}$

Cumprir esta meta passou a ser um grande desafio para gestores e chefes de estado, visto que fracassará se a sobrevivência não conseguir atingir milhões de crianças que vivem em condições miseráveis de vida e de saúde.

Na perspectiva de atingir os Objetivos do Milênio, o compromisso dos gestores, a disponibilidade de recursos e os esforços coletivos passam a ser medidas imprescindíveis, visto que a participação de agências internacionais isoladas não tem sido suficiente para garantir a vida destas crianças. Com este compromisso firmado, os países terão que reduzir, entre 2008 e 2015, as mortes infantis em ritmo mais rápido do que os registrados anteriormente. Deverão concentrar as ações naqueles mais pobres, onde as populações são vítimas de marginalização, de conflitos políticos e que a infra-estrutura de saneamento básico, acesso à água potável, alimentação e aos sistemas de saúde pública ainda são escassos ou inexistentes. ${ }^{1,6}$ 
Ainda com foco na redução da mortalidade infantil, Bellagio na Itália foi o cenário do encontro de pesquisadores de diversos países, que ampliaram as discussões acerca das ações que ocasionariam impacto nas mortes de crianças por doenças preveníveis. Preocuparam-se, também, com a redução das iniqüidades sociais e desigualdades da mortalidade entre populações pobres e ricas, com vistas à criação da segunda revolução em prol da sobrevivência infantil. ${ }^{7}$

\subsection{OS DETERMINANTES DOS ÓBITOS INFANTIS}

Para melhor compreensão da distribuição das mortes infantis e das desigualdades entre pobres e ricos, reforça-se a importância de conhecer os determinantes que influenciam a ocorrência destas mortes. Diversos fatores podem estar relacionados com o maior risco de óbitos infantis; como exemplos podem ser citados fatores biológicos (as condições de saúde da mãe e da criança), os sociais, os econômicos e os de escolaridade. ${ }^{8}$

Em países desenvolvidos, o acesso à educação com qualidade, as condições dignas de moradia, saneamento básico e a oferta de serviços de saúde pública foram fatores que influenciaram na redução dos óbitos de crianças, nas primeiras décadas do século XX. Tais melhorias passaram a existir mesmo antes das grandes descobertas tecnico-científicas da medicina moderna, o que credita às condições sociais, importante papel na diminuição da mortalidade infantil. ${ }^{2,9}$

Autores enfatizaram a existência de fatores que podem interferir na ocorrência de óbitos infantis, propondo um modelo analítico que identifica 
determinantes proximais, intermediários e distais, que representam fatores de risco importantes para a morbidade e morte das crianças. ${ }^{10}$

Os proximais que influenciam diretamente a sobrevivência são representados pelo estado de saúde da criança, incluindo o peso ao nascer, a situação nutricional e as práticas de aleitamento materno. Os determinantes distais, por sua vez, são agrupados em variáveis sócioeconômicas e de serviços de saúde. Como variáveis intermediárias os autores relacionaram os fatores idade, paridade e intervalo interpartal maternos. ${ }^{10,8}$

O peso ao nascer tem sido apontado por diversos autores como o mais importante determinante imediato do risco de morrer no primeiro ano de vida e, principalmente, no período perinatal; é também considerado pela OMS como relevante para a sobrevida infantil. A escolaridade materna e a renda familiar são também importantes determinantes da mortalidade infantil. ${ }^{11,12}$

Há mais de quatro décadas, foi estudada a influência da educação materna no declínio da mortalidade. O estudo ressalta que o melhor nível de instrução fortalece a mulher, tornando-a mais apta na prestação de cuidados aos filhos, além de permitir o desenvolvimento de novas maneiras de cuidar e fortalecer a ruptura com costumes e hábitos tradicionais. É atribuído à educação materna efeito independente na sobrevivência infantil, afirmando que: ${ }^{13}$

"A instrução da mãe aumenta a sua capacidade de conviver com o mundo, resultando em um efeito positivo 
na sobrevivência dos filhos. Modifica o equilíbrio tradicional dentro da família, que se reflete na repartição do consumo, inclusive de alimentos, por sexo e idade, a favor das mulheres e das crianças. Como conseqüência, os riscos de morte precoce se reduzem".

Ainda é reforçada a forte associação entre grau de escolaridade da mãe e parturição, sendo concluído que mulheres com melhores níveis de instrução tendem a ter um número menor de filhos, se comparadas com as de menor nível de instrução. ${ }^{13}$

A despeito da renda familiar, é conhecida a intensa relação entre desempenho econômico de uma sociedade e os seus padrões de morbimortalidade. Constatam-se, também; as conseqüências de seu impacto sobre as condições populacionais de bem estar e de vida e sua importância como variável social de consenso na sobrevivência infantil. ${ }^{12}$

Estudo refere que a renda está diretamente relacionada aos bens e serviços que interferem na condução e manutenção da saúde das crianças. São citados: a alimentação, moradia, acesso à água de boa qualidade, instalações sanitárias adequadas, além dos bens de consumo vestuário, equipamentos de comunicação e informação. ${ }^{12}$

Estudo na cidade de São Paulo dá ênfase à participação da renda familiar como determinante dos óbitos infantis. Mostra que, entre as crianças com pior situação sócio-econômica, a mortalidade infantil é duas vezes maior. $^{14}$

O adoecimento e a morte ocorrem com maiores freqüências nas populações mais pobres. Entretanto, a extensão das disparidades varia de 
país para país e torna estas condições piores muito mais para alguns do que para outros. $^{15}$

Estudo versa sobre a relação entre desenvolvimento e saúde, dando ênfase às contribuições do desenvolvimento no processo saúde-doença, com interferência significativa na diminuição dos óbitos infantis. ${ }^{16}$

\begin{abstract}
"Não existe controvérsia de que o desenvolvimento econômico tenha muito contribuído, por meio da história, para melhorar a saúde e prolongar a vida, bem antes que existisse a medicina científica ou moderna. Isto torna evidente, na redução gradual da mortalidade, que data desde o começo da Revolução Industrial". ${ }^{16}$
\end{abstract}

Assim pode-se informar que a saúde de uma população está diretamente associada à vantagem social, sendo a maior probabilidade de sobrevida em locais onde os recursos sociais e econômicos dos indivíduos são maiores. Contudo, é relevante reforçar que as iniqüidades são cada vez maiores quanto maiores forem as diferenças econômicas desta sociedade. ${ }^{15}$

\title{
1.3. A EVOLUÇÃO DA MORTALIDADE INFANTIL NO BRASIL DAS DESIGUALDADES
}

Nas últimas décadas, o coeficiente de mortalidade infantil no Brasil alcançou reduções significativas, com um declínio de aproximadamente $70 \%$, graças aos importantes investimentos econômicos e sociais que vêm ocorrendo no país, embora de maneira desigual entre as diferentes regiões brasileiras, onde grande parte da população ainda vive à margem de todos os benefícios proporcionados pelo desenvolvimento econômico. ${ }^{9,12,17}$ 
O declínio das mortes infantis no Brasil se deu no período de 19351940, quando a mortalidade infantil era 163 por 1.000 nascidos vivos (NV), caindo para 113,8 por 1.000 NV em 1970, com redução relativa de $30 \%$ e alcançando 68 por $1.000 \mathrm{NV}$ na década de 80 . Ainda em queda, a mortalidade infantil no país em 1993 era de 52 por 1.000 NV. ${ }^{1,2}$

Contudo, vale ressaltar que esta redução não ocorreu de modo uniforme em todas as regiões do Brasil, evidenciando os diferentes contrastes existentes entre elas. As regiões onde o nível de vida socioeconômico era mais elevado, com maior disponibilidade de serviços de saúde de qualidade, sem dúvida, garantiram melhores condições de sobrevivência, com boas repercussões na saúde infantil. ${ }^{2,8}$

A discrepante situação de vida das crianças nordestinas é configurada quando o declínio dos coeficientes de mortalidade infantil é avaliado, entre 1970 e 1980. Para o Brasil, enquanto a redução durante esta década foi de 22,7\%, na Região Sudeste, chegou a 27,5\%, com coeficiente, em 1980, igual a 88,9 por 1.000 NV. No Nordeste, reduziu-se apenas em $15 \%$, atingindo 124,5 por $1.000 \mathrm{NV}^{2,18}$

O excesso de mortes infantis, nas décadas de 80 e 90, no Nordeste, tem relação direta com a pobreza absoluta que, em 1987, abrangia cerca de $60 \%$ das famílias brasileiras que viviam abaixo da linha da pobreza. ${ }^{12}$

No Brasil, em face às disparidades sociais e regionais, que reproduzem as desigualdades entre populações, há significantes diferenças na mortalidade infantil. Os riscos diferenciados de morte são definidos pela não disponibilidade de ações eficazes e efetivas de proteção e reabilitação 
da saúde aos grupos que mais necessitam, tornando-os mais vulneráveis. $^{12,8}$

Apesar das desigualdades regionais, nos últimos 20 anos, destacamse avanços nos valores dos indicadores de mortalidade infantil em todo o país, que têm evoluído de maneira favorável e mais rapidamente do que fora observado nas décadas anteriores. Esta tendência de queda percebe-se, principalmente, entre os óbitos de crianças de 28 dias a menos de um ano de vida. $^{18,19,3,20}$

Segundo autores, os valores dos indicadores de saúde do Nordeste brasileiro distavam daqueles da Região Centro-Sul, com mortalidade infantil duas vezes maior, cobertura de serviços de saúde e saneamento ainda precários e níveis de escolaridade feminina, renda familiar e oportunidade de emprego, inferiores aos das cidades do Centro-Sul do país. ${ }^{19}$

\subsection{MORTALIDADE INFANTIL E SEUS COMPONENTES}

Para melhor compreender e avaliar o impacto das medidas adotadas no controle dos óbitos infantis, o coeficiente de mortalidade infantil é subdividido em dois componentes, mortalidade neonatal e pós-neonatal, respectivamente, incluindo óbitos até o $28^{\circ}$ dia de vida e aqueles do $29^{\circ}$ dia até menos de um ano. ${ }^{20}$

A mortalidade neonatal, por sua vez, apresenta dois componentes, mortalidade neonatal precoce que se refere aos óbitos de menores de sete dias de vida e suas causas estão relacionadas tanto às condições maternas - gravidez, parto, pré-natal - como também à assistência oferecida pelos 
serviços de saúde e aos problemas do recém nascido. O coeficiente de mortalidade neonatal tardia compreende os óbitos do oitavo dia até vinte e sete dias de vida, tendo como principais causas as doenças evitáveis. ${ }^{8,3,22}$

Estudos apontam que em vista da redução do componente pósneonatal, proporcionalmente há maior participação do neonatal na mortalidade.

No Rio de Janeiro, foi possível detectar declínio na mortalidade de recém nascidos, no primeiro ano de vida, que passou de 15,2/1.000 NV em 1994, para 10,5/1.000 NV em 2002. Houve redução de cerca de $40 \%$, considerada pequena quando comparada às tendências dos países desenvolvidos. A contribuição do componente neonatal precoce foi em torno de $52,3 \%$, na mortalidade infantil do Estado. ${ }^{11}$

Uma vez relacionada a fatores biológicos maternos, problemas na gravidez e parto e também à disponibilidade de assistência perinatal, a redução das mortes nos primeiros 27 dias, se comparadas às pós-neonatais, tem sido de difícil alcance. Tal fato associa-se ao custo elevado e dependência de investimentos em instrumentos de alta complexidade tecnológica e decisão política por parte dos gestores.

A mortalidade pós-neonatal, por sua vez, relaciona-se principalmente às doenças infecciosas e podem ser prevenidas, como as doenças diarréicas, desnutrição e pneumonias, que são mais vulneráveis às intervenções do setor de saúde e das ações de ampliação do saneamento básico. ${ }^{8,23}$ 
Diante destas características, as mortes neonatais e pós-neonatais têm magnitudes diferenciadas entre países ou regiões, isto porque há predomínio proporcionalmente do componente neonatal, nos mais desenvolvidos. Esta situação é resultante do fato de os fatores de risco já estarem controlados (boa atenção à mulher grávida e ao recém nascido, pelo sistema de saúde, boas condições socioeconômicas e biológicas maternas). Nos países em desenvolvimento, observa-se o predomínio proporcional do componente pós-neonatal, ligado às doenças condicionadas às precárias condições de vida.

\subsection{A MORTALIDADE PERINATAL E SUAS REPERCUSSÕES NA SAÚDE DA MULHER GRÁVIDA E DE SEU RECÉM NASCIDO}

A análise da mortalidadeperinatal permite a investigação das causas de morte que acontecem antes do nascimento (mortes ou perdas fetais após 22 semanas de gestação ou peso no mínimo igual a 500g) e suas intercorrências durante a gestação, o trabalho de parto e parto. Assim, as mortes perinatais englobam as perdas fetais e as mortes neonatais precoces.

O termo mortalidade perinatal foi proposto por Peller em 1940, e compreendia o conjunto dos nascidos mortos (morte do feto a partir de 28 semanas de gestação) e as mortes na primeira semana de vida. Na opinião do autor, havia necessidade de analisá-los como uma unidade estatística, 
pois apresentavam fatores de risco semelhantes e referiam-se a um período de grande importância no ciclo vital. $^{24}$

É importante enfatizar que as perdas fetais não estão inseridas no contexto da mortalidade infantil, mesmo tendo causas semelhantes e mesmos fatores de risco. Assim, englobando ambos os eventos, foi criado o coeficiente de mortalidade perinatal, que possibilita a avaliação da eficácia do processo reprodutivo, das condições epidemiológicas, socioeconômicas e culturais da gravidez e do parto e da prestação de atenção à saúde perinatal. $25,26,8$

A importância da contribuição dos óbitos fetais na mortalidade perinatal é enfatizada devido serem em maior número do que os neonatais precoces. Estas mortes traduzem falhas relacionadas ao pré-natal, ao manejo obstétrico e às horas que antecedem o parto. Grande parte dos óbitos fetais como dos neonatais precoces partilham da possibilidade de serem evitados, em mais da metade dos casos. ${ }^{27}$

Do ponto de vista da causalidade, chamam a atenção os fatores idade e escolaridade materna, baixa renda familiar, história reprodutiva desfavorável e qualidade da atenção no pré-natal. Nos países onde estas condições são mais precárias e desfavoráveis, há maior ocorrência dos óbitos perinatais e mais da metade é representada pelos óbitos fetais. ${ }^{28}$

\subsection{FORTALEZA: O CENÁRIO DO ESTUDO}


No Ceará, no decorrer dos últimos 15 anos, muitos avanços foram alcançados nos resultados dos indicadores da saúde materno-infantil. Pode ser observado declínio importante da mortalidade infantil, em virtude, dentre outros motivos, da priorização das ações básicas na assistência integral à saúde da criança. Entre 1987 e 1990, esta redução foi de 33\%, com maior repercussão no componente pós-neonatal. ${ }^{8,17,29,30}$

Em 1987, quando foi realizada a 1a Pesquisa de Saúde Materna Infantil no Ceará -PESMIC- foi constatado um cenário caótico, com coeficiente de mortalidade infantil de 104 por 1.000 NV e a causa básica diarréia foi responsável pela metade dos óbitos. Pode ser observada, também, que a maior concentração dos óbitos estava no período pósneonatal e que a contribuição do componente neonatal era de apenas $28 \% .^{31,12}$

Esforços coletivos foram imperiosos para a implantação das ações necessárias e importantes para modificar a situação de saúde da criança, no Estado. Destacam-se a criação do Programa Agente de Saúde, em 1987, a utilização da Terapia de Rehidratação Oral - TRO - em larga escala nos casos de diarréias e a criação e intensificação das campanhas de vacinação. $^{31,12}$

A redução das mortes neonatais tem ocorrido de forma mais lenta, em todo o Estado, principalmente as que ocorrem na primeira semana de vida. A contribuição proporcional do componente neonatal para a mortalidade infantil em 1987 era 28\%, passando para 46\%, em 1990, e 57\%, em 1994. Este aumento explica que ações pensadas e aplicadas ao componente pós- 
neonatal não podem ser as mesmas para os recém nascidos. Estas pesquisas aconteceram em 1987, 1990 e 1994 (PESMIC I, II e III) em cerca de 8.000 famílias cearenses. $^{32,12}$

Por todos estes anos, foi possível reduzir a mortalidade infantil no Estado, em aproximadamente 82,7\%, ou seja, de 104 por mil NV em 1987 para 18 por mil NV em 2005. Além do significativo declínio nos coeficientes, pode-se observar ainda mudança também em relação às causas das mortes infantis. As por diarréia decresceram para $10 \%$ e o componente neonatal que antes tinha pouca relevância (28\%) passou a contribuir em $65 \%$ das mortes, assumindo, maior importância epidemiológica, na medida em que a mortalidade infantil decresceu. ${ }^{31,32,33,34}$

Em 1995, foi realizado estudo de coorte hospitalar, com objetivo de estimar indicadores de saúde perinatal, com 40.712 nascimentos ocorridos em hospitais da rede pública (Federais, Estaduais e Municipais) e particulares conveniados com o SUS, em Fortaleza. $^{8}$

A análise mostrou precárias condições da assistência perinatal oferecida nas unidades de saúde da cidade, apontando importantes problemas ligados à organização do sistema de saúde e à qualidade da atenção prestada às gestantes, durante o pré-natal, trabalho de parto e parto e no atendimento aos recém-nascidos em sala de parto e unidade neonatal. Mostrou, ainda, a mortalidade perinatal e neonatal e a proporção das mortes evitáveis, baseando-se nos dados coletados de prontuários, registros hospitalares, declarações de óbitos e de nascidos vivos, em maternidades públicas e conveniadas com o SUS. ${ }^{8,35,28}$ 
Os dados revelaram altos coeficientes de mortalidade perinatal $(32,8$ por mil nascimentos), neonatal precoce (15,2 por mil NV) e fetal $(17,9$ por mil nascimentos). Parte dos óbitos (34\%) era passível de redução, pois equivaliam a 452 mortes evitáveis. ${ }^{8,35}$

A alta proporção de perdas fetais com peso maior ou igual a $2500 \mathrm{~g}$ $(32,5 \%)$ contrastou com o alto percentual de cobertura pré-natal, o que sugere dificuldades na identificação do risco da gestante, nos momentos próximos ao nascimento, com problemas relacionados com a qualidade desse atendimento ou com a falta de um sistema de atenção regionalizado e ainda com falta da garantia de referência para centros mais especializados, para as gestantes de risco. ${ }^{8,35}$ 


\section{JUSTIFICATIVA}

O interesse em estudar a evolução das mortes perinatais de Fortaleza, de 1995 a 2005, parte de sua importância como indicador de saúde materno infantil. Possibilita a avaliação da qualidade dos cuidados dispensados ao binômio mulher/concepto, no pré-natal e no parto, e ao recém nascido, nos primeiros sete dias de vida. ${ }^{28}$

Com o estudo de 1995, evidenciou-se um cenário caótico das condições da assistência perinatal, no município, revelando problemas na organização do sistema de saúde, na qualidade da atenção prestada às gestantes no pré-natal, trabalho de parto e parto, e no atendimento aos recém-nascidos em sala de parto e unidade neonatal ${ }^{8,35}$. Em 2005, outro estudo foi realizado, com intuito de analisar os novos indicadores perinatais, em Fortaleza, tendo em vista os investimentos aplicados nos programas relacionados à saúde da mulher grávida e à do recém nascido, ao longo destes 10 anos $^{60}$

Portanto, a comparação da saúde perinatal nos dois momentos foi a grande motivação para a realização de um terceiro estudo que buscava o entendimento das possíveis mudanças ocorridas na saúde perinatal em Fortaleza, neste intervalo decenal. 


\section{OBJETIVOS}

\subsection{Geral}

Avaliar a evolução dos indicadores de saúde perinatal referentes aos nascimentos hospitalares de Fortaleza, Ceará, ocorridos em 1995 e em 2005

\subsection{Específicos}

Analisar as mudanças que ocorreram na saúde perinatal hospitalar em Fortaleza, Ceará, em dois momentos, 1995 e em 2005.

Comparar a saúde perinatal nos dois anos (1995 e 2005), considerando as variáveis peso ao nascer, tipo de parto e idade da mãe. 


\section{METODOLOGIA}

\subsection{Tipo de Estudo}

Trata-se de um estudo epidemiológico, do tipo ecológico, que observa a evolução da saúde perinatal em Fortaleza, de 1995 a2005, a partir da análise dos resultados de dois estudos de base hospitalar. Todos os nascimentos foram acompanhados desde o parto até a respectiva alta onde ocorreu o evento ou óbito em hospital ${ }^{8,35,60}$.

\subsection{População}

Foi formada por todos os nascimentos e respectivos óbitos perinatais ocorridos em hospitais públicos e particulares, conveniados com o SUS, no município de Fortaleza, CE, em 1995 e em 2005, disponíveis em dois bancos de dados já existentes. Portanto, são dados secundários e fazem parte da presente pesquisa, 40.712 nascimentos hospitalares (vivos e perdas fetais) ocorridos em 1995, em 17 hospitais, e 34.883 nascimentos hospitalares (vivos e perdas fetais) ocorridos em 2005.

\subsection{Coleta dos Dados}

Foram utilizados dados dos dois bancos pertencentes ao Núcleo de Ensino, Assistência e Pesquisa da Infância César Victora - NEAPI da Universidade Federal do Ceará - UFC. 
Em 1995 foram estudados 40.712 nascidos vivos e perdas fetais com peso igual ou superior a 500 gramas de 17 hospitais-maternidades, públicos ou particulares conveniados com o Sistema Único de Saúde (SUS) de Fortaleza, responsáveis por cerca de 80 a $85 \%$ dos partos no município.

Após 10 anos, em 2005, foi realizada nova pesquisa, onde foram estudados 34.883 nascimentos vivos e perdas fetais com peso igual ou superior a 500 gramas de 15 hospitais-maternidades, públicos ou particulares conveniados com o Sistema Único de Saúde (SUS) de Fortaleza, responsáveis por cerca de $90 \%$ dos partos no município.

Os nascidos vivos que apresentaram agravos e necessitaram transferência foram transportados para os dois hospitais pediátricos de referência terciária que possuíam UTI neonatal; um deles público e o outro, conveniado com o SUS/Fortaleza.

Para a coleta dos dados foram elaborados dois formulários: um para informações sobre os nascimentos vivos e perdas fetais e mães (Anexo 1). O outro instrumento permitia analisar as declarações de óbito (DO) e os dados dos prontuários do recém nascido (Anexo 2).

As variáveis maternas coletadas foram: idade, realização e no de consultas de pré-natal e tipo de parto. As variáveis referentes ao recém nascido foram: data de nascimento, peso ao nascer, sexo, condição de nascimento (vivo ou perda), dados sobre transferência para outro hospital e revisão do prontuário para averiguar as condições associadas ao óbito. 
As coletas foram realizadas por pesquisadores de campo, previamente treinados e que realizavam visitas aos hospitais duas vezes por semana.

Mensalmente, realizava-se reunião entre todos os participantes, com o objetivo de avaliar o desenvolvimento da pesquisa. Todos os recém nascidos foram acompanhados, no hospital, até o desfecho, alta ou óbito. Os recém nascidos que receberam altas não foram acompanhados após a data da alta. Todavia, os nascidos vivos transferidos ou que permaneceram hospitalizados por algum agravo foram acompanhados até o momento do óbito ou da alta.

As fontes dos dados foram:

a) livro de anotações do berçário e da sala de parto da maternidade. Em caso de dúvidas, consultou-se a Declaração de Nascido Vivo (DN). Cabe ressaltar que o Sistema de Informação sobre Nascido Vivo (SINASC) do Ministério da Saúde encontrava-se, à época, em fase de implantação.

b) prontuário do recém nascido e de sua mãe na maternidade, nos casos de morte da criança na maternidade onde ocorreu o parto;

c) prontuário do recém-nascido dos hospitais pediátricos de referência, nos casos de óbitos fora da maternidade;

d) declaração do óbito fetal e do neonatal ocorrido nos hospitaismaternidades e hospitais pediátricos de referência.

Os indicadores perinatais comparados nos dois estudos foram:

- Ocorrência de baixo peso ao nascer

- Ocorrência de muito baixo peso ao nascer 
- Ocorrência de extremo baixo peso ao nascer

- Ocorrência de peso desfavorável ao nascer

- Ocorrência de peso insuficiente ao nascer

- Coeficiente de mortalidade perinatal

- Coeficiente de mortalidade fetal

- Coeficiente de mortalidade neonatal precoce

- Proporção de baixo peso ao nascer nos óbitos neonatais precoces

- Proporção de muito baixo peso ao nascer nos óbitos neonatais precoces

- Coeficiente de mortalidade neonatal precoce segundo peso ao nascer

- Nascidos vivos por peso ao nascer e incidência de tipo de parto

- Proporção de partos de adolescentes

Quanto ao processamento e análise dos resultados, os mesmos foram arquivados e elaborados em base eletrônica EPI-INFO 6.04. Análises parciais e produção de relatórios foram feitos ao final de cada trimestre até o final do estudo. 
HOSPITAIS-MATERNIDADES QUE PARTICIPARAM DOS ESTUDOS

DE 1995 E 2005

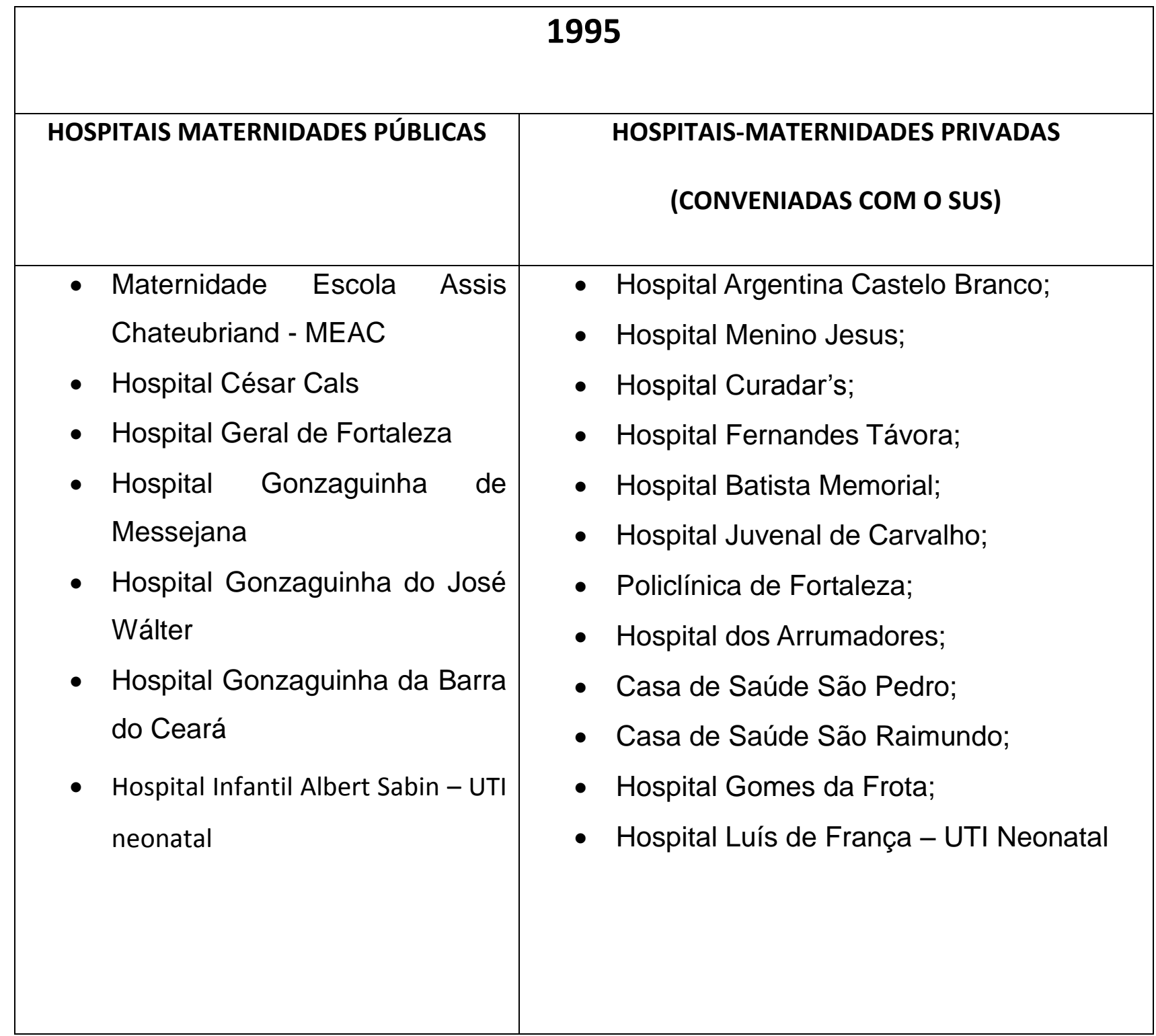




\begin{tabular}{|c|c|}
\hline \multicolumn{2}{|c|}{2005} \\
\hline HOSPITAIS MATERNIDADES PÚBLICAS & $\begin{array}{l}\text { HOSPITAIS-MATERNIDADES PRIVADAS } \\
\text { (CONVENIADAS COM O SUS) }\end{array}$ \\
\hline $\begin{array}{l}\text { - } \text { Maternidade Ascola } \\
\text { - } \text { Hospital César Cals } \\
\text { - Hospital Geral de Fortaleza } \\
\text { - Hospital Gonzaguinha de Messejana } \\
\text { - Hospital Gonzaguinha do José Wálter } \\
\text { - Hospital Gonzaguinha da Barra do } \\
\text { Ceará } \\
\text { - Hospital Nossa Senhora da } \\
\text { Conceição } \\
\text { - Hospital Infantil Albert Sabin - UTI } \\
\text { neonatal externa } \\
\text { Hospital Waldemar Alcântara - UTI } \\
\text { neonatal externa }\end{array}$ & $\begin{array}{l}\text { - Hospital Argentina Castelo Branco; } \\
\text { - Hospital Menino Jesus; } \\
\text { - Hospital Cura'dars; } \\
\text { - Hospital Fernandes Távora; } \\
\text { - Hospital Batista Memorial; } \\
\text { - Hospital Juvenal de Carvalho; } \\
\text { - Hospital Angeline }\end{array}$ \\
\hline
\end{tabular}




\subsection{Análise dos Dados}

Foram elaborados e analisados indicadores dos dois anos (1995 e 2005), comparados entre si e calculadas as diferenças.

\subsection{Aspectos Éticos}

O estudo foi aprovado pelo Comitê de Ética em Pesquisa da Faculdade de Saúde Pública da Universidade de São Paulo - (Anexo 1 ) .Para a utilização dos dois bancos foi concedido termo de fiel depositário (Anexo 2 ). 


\section{RESULTADOS}

A comparação da proporção dos nascimentos ocorridos em 2005 com os do ano de 1995 possibilita a percepção das mudanças que aconteceram em Fortaleza na atenção perinatal e, principalmente, do fortalecimento do setor público nos dez anos.

Em 1995 ocorreram 40.712 nascimentos, sendo que mais da metade, $27.510(67,6 \%)$ em hospitais conveniados com o SUS e apenas 13.202 (32.4\%) em hospitais públicos. Fizeram parte do primeiro estudo (1995) dezessete hospitais, sendo seis da rede pública (um federal, dois estaduais e três municipais) $(35,3 \%)$ e onze eram conveniados com o SUS $(64,7 \%)$. Em 2005, quando foi realizado o segundo estudo, participaram catorze hospitais, sendo a metade instituições pública (uma federal, dois estaduais e quatro municipais) e a outra metade, hospitais conveniados com o SUS. Nas instituições públicas ocorreu um total de 21.989 nascimentos $(71,7 \%)$ e nas conveniadas com o SUS houve apenas $8.689(28,3 \%)$.

Uma melhor distribuição dos nascimentos pode ser observada nos hospitais públicos em 2005, quando se comparam os dois momentos da saúde perinatal em Fortaleza. Nos três hospitais distritais, os “Gonzaguinhas", pertencentes à rede municipal de saúde, em 1995, foram registrados 3.260 nascimentos $(8,0 \%)$ e, em 2005, 8.518 nascimentos, (27,7\%). A proporção de nascimentos em 2005 nestes hospitais foi 3,4 vezes a de 1995. 
Uma redução de $18.7 \%$ no número de nascimentos ocorreu na Maternidade Escola Assis Chateaubriand- MEAC, o local onde mais ocorreram partos no município, nos dois anos. Em 1995, sozinha perfez $17,6 \%$ de todos os nascimentos. Quanto aos hospitais conveniados, detectou-se um decréscimo de mais da metade $(58,1 \%)$ dos nascimentos em 2005.

Também nota-se que alguns hospitais conveniados com o SUS que participaram do estudo em 1995, e onde aconteceram $11.446(28,0 \%)$ dos partos de Fortaleza, não mais existiam em 2005 ou foram descredenciados do atendimento obstétrico e perinatal. Vale salientar que eles representavam $(41,6 \%)$ do total de partos ocorridos nos hospitais credenciados. 
Tabela 1- Distribuição do número e proporção (\%) dos nascimentos segundo hospital-maternidade em 1995 e 2005. Fortaleza-Ceará.

\begin{tabular}{|c|c|c|c|c|c|}
\hline \multirow[t]{2}{*}{ Hospital Público } & \multicolumn{2}{|c|}{1995} & \multicolumn{2}{|c|}{2005} & \multirow{2}{*}{$\begin{array}{c}\text { Variação } \\
\%\end{array}$} \\
\hline & $\mathrm{N}$ & $\%$ & $\mathrm{~N}$ & $\%$ & \\
\hline $\begin{array}{c}\text { Maternidade Escola Assis } \\
\text { Chateaubriand }\end{array}$ & 7.197 & 17,6 & 4376 & 14,3 & $-18,7$ \\
\hline $\begin{array}{l}\text { Hospital Geral de } \\
\text { Fortaleza* }\end{array}$ & $2^{*}$ & ------ & 1383 & 4,5 & \\
\hline Hospital César Cals & 2.748 & 6,7 & 4707 & 15,3 & 128,3 \\
\hline $\begin{array}{l}\text { Hospital Nossa Senhora } \\
\text { da Conceição* }\end{array}$ & ------ & ----- & 3005 & 9,8 & ------- \\
\hline $\begin{array}{l}\text { Hospital Gonzaguinha } \\
\text { deMessejana }\end{array}$ & 1613 & 3,9 & 3950 & 12,9 & 230,7 \\
\hline Hospital Gonzaguinha & 817 & 2,0 & 2265 & 7,4 & 270,0 \\
\hline Hospital Gonzaguinha & 830 & 2,0 & 2303 & 7,5 & 275,0 \\
\hline Total Hospitais Públicos & 13.202 & 32,4 & 21.989 & 71,7 & 121.3 \\
\hline \multirow[b]{2}{*}{$\begin{array}{c}\text { Hospitais Conveniados com o } \\
\text { SUS }\end{array}$} & \multicolumn{2}{|c|}{1995} & \multicolumn{2}{|c|}{2005} & Variação \\
\hline & $\mathrm{N}$ & $\%$ & $\mathrm{~N}$ & $\%$ & $\%$ \\
\hline $\begin{array}{l}\text { Hospital Fernandes } \\
\text { Távora }\end{array}$ & 2087 & 5,1 & 829 & 2,7 & $-47,0$ \\
\hline Hospital Juvenal Carvalho & 2012 & 4,9 & 1233 & 4,0 & $-18,3$ \\
\hline Hospital Menino Jesus & 4362 & 10,7 & 945 & 3,1 & - 71,02 \\
\hline Hospital Arg.Castelo & 3445 & 8,4 & 1333 & 4,4 & $-47,6$ \\
\hline $\begin{array}{c}\text { Rranrn } \\
\text { Hospital Batista }\end{array}$ & 953 & 2,3 & 1147 & 3,7 & 60,8 \\
\hline Hospital Cura'Dars & 3199 & 7,8 & 3097 & 10,1 & 29,4 \\
\hline Hospital Angeline ${ }^{* *}$ & ---- & ----- & 105 & 0,3 & ------ \\
\hline Policlínica**** & 5117 & 12,5 & 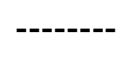 & -------- & ------- \\
\hline Hospital Gomes da & 2426 & 5,9 & -------- & ------- & ------- \\
\hline $\begin{array}{l}\text { Frntata*k** } \\
\text { H.Arrumadores }\end{array}$ & 1916 & 4,7 & -1 & - & -------- \\
\hline C.S.São Pedro**** & 1423 & 3,4 & -------- & --- & -------- \\
\hline 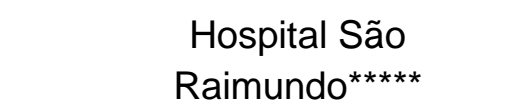 & 564 & 1,3 & --- & -- & \\
\hline
\end{tabular}




\begin{tabular}{c|c|c|c|c|c}
\hline $\begin{array}{c}\text { Total Hospitais } \\
\text { Conveniados com SUS }\end{array}$ & 27.510 & 67,6 & 8.689 & 28,3 & $-58,1$ \\
\hline Total & 40712 & 100,0 & $30678^{\star * \star * \star}$ & 100,0 & $-\cdots------$ \\
\hline
\end{tabular}

${ }^{*}$ Hospital não existia em 1995

** Hospital não participou do estudo em 1995

****Hospital não existe mais

${ }^{* * * * *}$ Hospital em 2005 não fazia mais atendimento perinatal

****** Foram excluídos 49 casos semidentificação do hospital

Gráfico 1 - Proporção (\%) dos nascimentos hospitalares segundo categoria dos hospitais Fortaleza-Ceará, 1995 e 2005

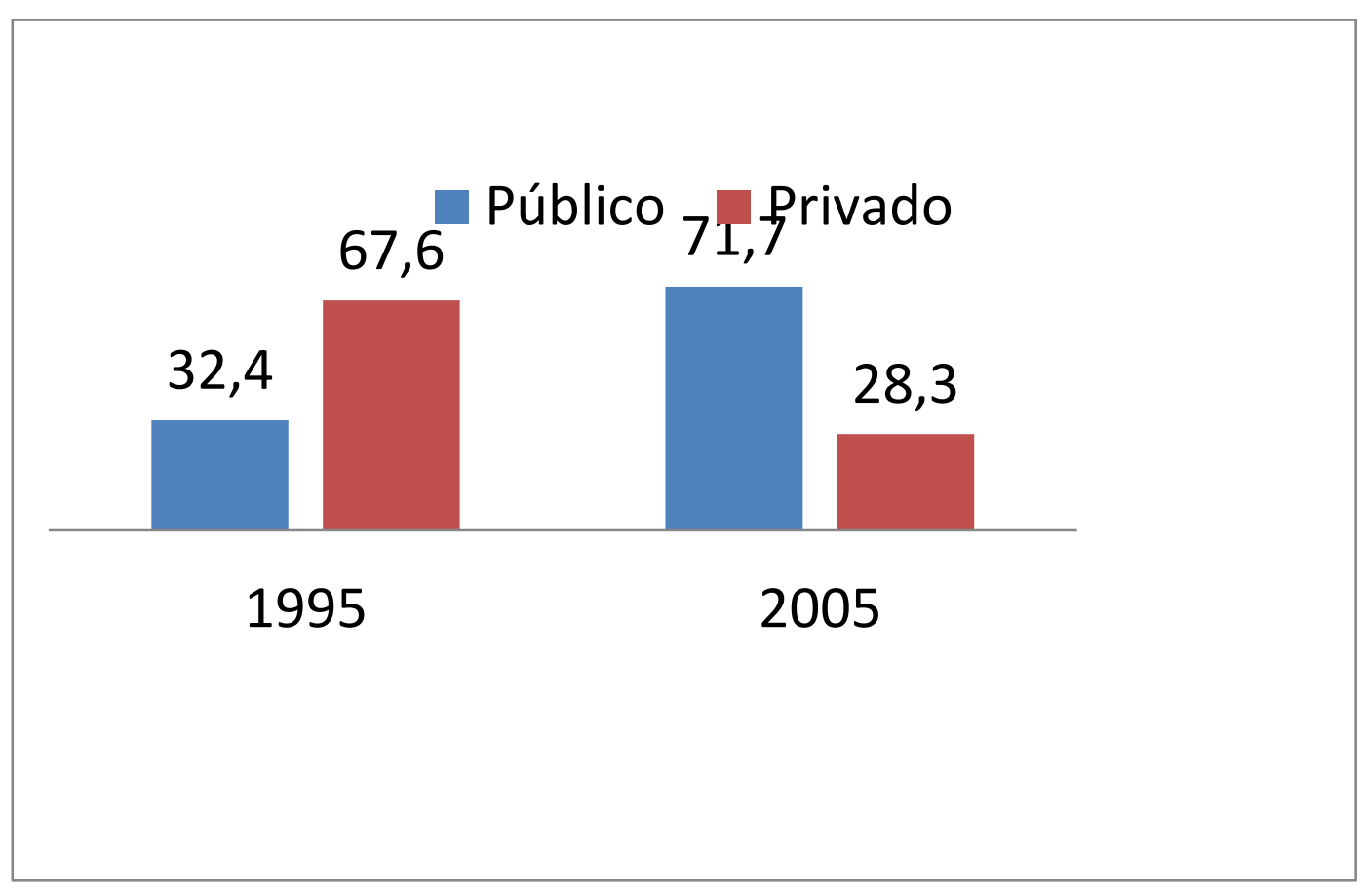

A distribuição dos nascimentos segundo peso ao nascer e ocorrência de perdas fetais nos dois anos mostrou variações nas diferentes faixas de peso. Dos 40.712 nascimentos hospitalares ocorridos em 1995, a proporção de perdas fetais foi de $1,8 \%$, enquanto em 2005 , dos 30.567 nascimentos, 
esta proporção foi de $1,5 \%$. A redução das perdas fetais para todas as faixas de peso nos dez anos (1995-2005) foi 16,6\%.

Entre o grupo de baixo peso ao nascer, em 1995, a variação de perdas fetais foi de $13,8 \%$, passando de $68,6 \%$ para $78,1 \%$. Quanto ao grupo com peso igual ou maior que $2500 \mathrm{~g}$, no período estudado (19952005), foi observada redução de 30,2\% das mortes fetais (Tabela 2 ).

Chama-se atenção para a faixa de peso de 3.000 a $3.999 \mathrm{~g}$, que foi a que apresentou maior redução, igual a 41,9\% (Tabela 2).

Em 1995, observou-se que a proporção de perdas fetais com peso inferior a $2.500 \mathrm{~g}(68,6 \%)$ foi 2 vezes, ao ser comparada com a proporção de perdas com peso adequado. Em 2005, esta relação foi 3,5 vezes.

Tabela 2 - Distribuição do número e proporção(\%) das perdas fetais hospitalares segundo peso ao nascer (em gramas) em 1995 e 2005. Fortaleza-Ceará.

\begin{tabular}{l|cc|cc|c}
\hline \multicolumn{1}{c|}{ Peso ao } & \multicolumn{2}{|c|}{1995} & \multicolumn{2}{c|}{2005} & Variação \\
Nascer $(\mathrm{g})$ & $\mathrm{N}$ & $\%$ & $\mathrm{~N}$ & $\%$ & $\%$ \\
\hline $500-999$ & 199 & 27,6 & 145 & 32,4 & 17,3 \\
$1000-1499$ & 128 & 17,8 & 79 & 17,7 & ------- \\
$1500-1999$ & 95 & 13,2 & 70 & 15,7 & 18,9 \\
$2000-2499$ & 73 & 10,1 & 55 & 12,3 & 21,7 \\
$2500-2999$ & 95 & 13,2 & 47 & 10,5 & $-20,4$ \\
$3000-3999$ & 117 & 16,2 & 42 & 9,4 & $-41,9$ \\
4000 ou mais & 14 & 1,9 & 9 & 2,0 & 5,2 \\
\hline$<2500$ & 495 & 68,6 & 349 & 78,1 & 13,8 \\
$>=2500$ & 226 & 31,4 & 98 & 21,9 & $-30,2$ \\
\hline Total & 721 & 100 & 447 & 100 & ------- \\
& & &
\end{tabular}


Observou-se uma redução nos dez anos (1995-2005) na ocorrência de óbitos neonatais precoces hospitalares em Fortaleza. Em 1995, foram observados 602 óbitos neonatais precoces entre o total de 39.991 nascidos vivos. A proporção de óbitos neonatais precoces foi de 1,5\%. Em 2005, foram detectadas 266 mortes no período neonatal precoce em 30.120 nascidos vivos, sendo a proporção destas mortes menor que $1,0 \%$. Constatou-se uma redução de $46,6 \%$ das mortes neonatais precoces de 2005 em relação a 1995.

Os grupos de peso 1.000 a $1.499 \mathrm{~g} ., 1.500$ a $1.999 \mathrm{~g}$ e o de 2000 a $2.499 \mathrm{~g}$ apresentaram as respectivas reduções, $35,8 \%, 42,3 \%$ e $35,5 \%$. Os óbitos neonatais precoces com peso entre 3.000 e $3.999 \mathrm{~g}$ variaram no período estudado, com aumento de $41,9 \%$. As proporções de mortes neste grupo em 1995 e 2005 foram respectivamente 9,3\% e 13,2\% (Tabela 3). 
Tabela 3 - Distribuição do número e proporção(\%)de óbitos neonatais precoceshospitalares segundo peso ao nascer (em gramas) em 1995 e 2005. Fortaleza-Ceará.

\begin{tabular}{|c|c|c|c|c|c|}
\hline \multirow{2}{*}{$\begin{array}{c}\text { Peso ao } \\
\text { Nascer (g) }\end{array}$} & \multicolumn{2}{|c|}{1995} & \multicolumn{2}{|c|}{2005} & \multirow{2}{*}{$\begin{array}{c}\text { Variação } \\
\%\end{array}$} \\
\hline & $\mathrm{N}$ & $\%$ & $\mathrm{~N}$ & $\%$ & \\
\hline $500-999$ & 161 & 26,7 & 111 & 41,7 & $+56,1$ \\
\hline $1000-1499$ & 187 & 31,0 & 53 & 19,9 & $-35,8$ \\
\hline $1500-1999$ & 114 & 18,9 & 29 & 10,9 & $-42,3$ \\
\hline $2000-2499$ & 46 & 7,6 & 13 & 4,9 & $-35,5$ \\
\hline $2500-2999$ & 33 & 5,4 & 22 & 8,3 & $+34,9$ \\
\hline $3000-3999$ & 56 & 9,3 & 35 & 13,2 & $+41,9$ \\
\hline 4000 ou mais & 05 & 0,8 & 03 & 1,1 & $+37,5$ \\
\hline$<2500$ & 508 & 84,4 & 206 & 77,5 & $-8,1$ \\
\hline$>=2500$ & 94 & 15,6 & 60 & 2,5 & $-44,2$ \\
\hline Total & 602 & 100,0 & 266 & 100,0 & ------ \\
\hline
\end{tabular}

Entre os 40.712 nascimentos hospitalares ocorridos em Fortaleza, no ano de 1995, 39.354 sobreviveram até o sétimo dia de vida, uma proporção de 96,6\%. Em 2005 dos 30.567 nascimentos, a proporção de sobreviventes foi de $97,6 \%$, ou seja, 29.854 .

Chama-se atenção para o aumento importante na sobrevivência que pode ser detectado na faixa de peso de 1.000 a $1.499 \mathrm{~g}$., entre os dois anos $233,3 \%$ (Tabela 4). 
Quanto à proporção de sobreviventes com peso entre 1.000 a $1.499 \mathrm{~g}$ em 2005 observou-se que foi 3 vezes maior quando comparada com 1995.

Também pode ser detectado uma maior sobrevivência entre o recém nascidos de baixo peso (peso > que 2.500g.) que tiveram um aumento de $37,0 \%$ quando comparado os dois anos (Tabela 4).

Tabela 4 - Distribuição do número e proporção(\%) dos nascimentos hospitalares sobreviventes até o $7^{0}$ diade vida segundo peso ao nascer (em gramas) em 1995 e 2005. Fortaleza-Ceará.

\begin{tabular}{|c|c|c|c|c|c|}
\hline $\begin{array}{c}\text { Peso ao } \\
\text { Nascer }(\mathrm{g})\end{array}$ & $\begin{array}{l}\text { Sobrel } \\
\text { até o }\end{array}$ & $\begin{array}{l}\text { entes } \\
\text { dia }\end{array}$ & $\begin{array}{c}\text { Sobrev } \\
\text { até } 0\end{array}$ & $\begin{array}{l}\text { entes } \\
\text { dia }\end{array}$ & $\begin{array}{c}\text { Variação } \\
\%\end{array}$ \\
\hline $500-999$ & 17 & ------ & 99 & 0,3 & ----- \\
\hline $1000-1499$ & 130 & 0,3 & 242 & 1,0 & 233,3 \\
\hline $1500-1999$ & 460 & 1,2 & 550 & 1,8 & 50,0 \\
\hline $2000-2499$ & 1.841 & 4,8 & 1.655 & 5,5 & 14,5 \\
\hline $2500-2999$ & 7.764 & 19,7 & 6.342 & 1,2 & 7,6 \\
\hline $3000-3999$ & $26.3 s$ & 67,0 & 19.14 & 64,1 & $-4,3$ \\
\hline 4000 ou mais & 2.752 & 7,0 & 1.826 & 6,1 & $-12,8$ \\
\hline$<2500$ & 2.448 & 6,2 & 2.546 & 8,5 & 37,0 \\
\hline$>=2500$ & 36.90 & 93,8 & 27.308 & 91,5 & $-2,5$ \\
\hline Total & 39354 & 100 & 29.854 & 100 & -------- \\
\hline
\end{tabular}


A mortalidade perinatal hospitalar no Município de Fortaleza entre 1995 e 2005 reduziu-se em 29\%. Em 1995, o coeficiente de mortalidade perinatal era 32,8 por mil nascimentos e passou, em 2005, a 23,3 por mil. Em relação aos coeficientes segundo peso ao nascer observam-se reduções importantes entre os recém nascidos com peso de 1.000 a $1.499 \mathrm{~g}$ e de 1.500 a $1.999 \mathrm{~g}(50,1 \%$ e $51,2 \%$, respectivamente). Entretanto, apesar de terem sido observadas essas quedas na categoria de baixo peso ao nascer, chamam a atenção os recém nascidos com extremos baixos pesos (500 a $999 \mathrm{~g})$, com a menor redução detectada $(24,4 \%)$, ao longo desses anos, com exceção dos coeficientes relativos aos nascidos com no mínimo $4000 \mathrm{~g}$ (redução de $4,4 \%$ ). Vale ressaltar ainda a queda de $38,5 \%$, ocorrida na faixa de peso de 3000 a 3999g, uma vez que as chances de sobrevivência neste grupo são muito maiores (Tabela 5).

Tabela 5 - Coeficientes de mortalidade hospitalar perinatal (por mil nascimentos) segundo peso ao nascer (em gramas), entre 1995 e 2005. Fortaleza-Ceará.

\begin{tabular}{c|rrc}
\hline $\begin{array}{c}\text { Peso ao Nascer } \\
\text { (em gramas) }\end{array}$ & 1995 & 2005 & Redução (\%) \\
\hline 500a 999 & 954,9 & 721,1 & 24,5 \\
1.000 a 1.499 & 707,8 & 352,9 & 50,1 \\
1.500 a 1.999 & 312,4 & 152,5 & 51,2 \\
2000 a 2499 & 60,7 & 39,5 & 34,9 \\
2500 a 2999 & 16,2 & 10,8 & 33,3 \\
3000 a 3999 & 6,5 & 4,0 & 38,5 \\
$\geq 4000$ & 6,8 & 6,5 & 4,4 \\
\hline Total & 32,8 & 23,3 & 29,0 \\
\hline
\end{tabular}


Gráfico 2-Coeficientes de mortalidade hospitalar perinatal (por mil nascimentos) segundo peso ao nascer (em gramas), entre 1995 e 2005. Fortaleza-Ceará.

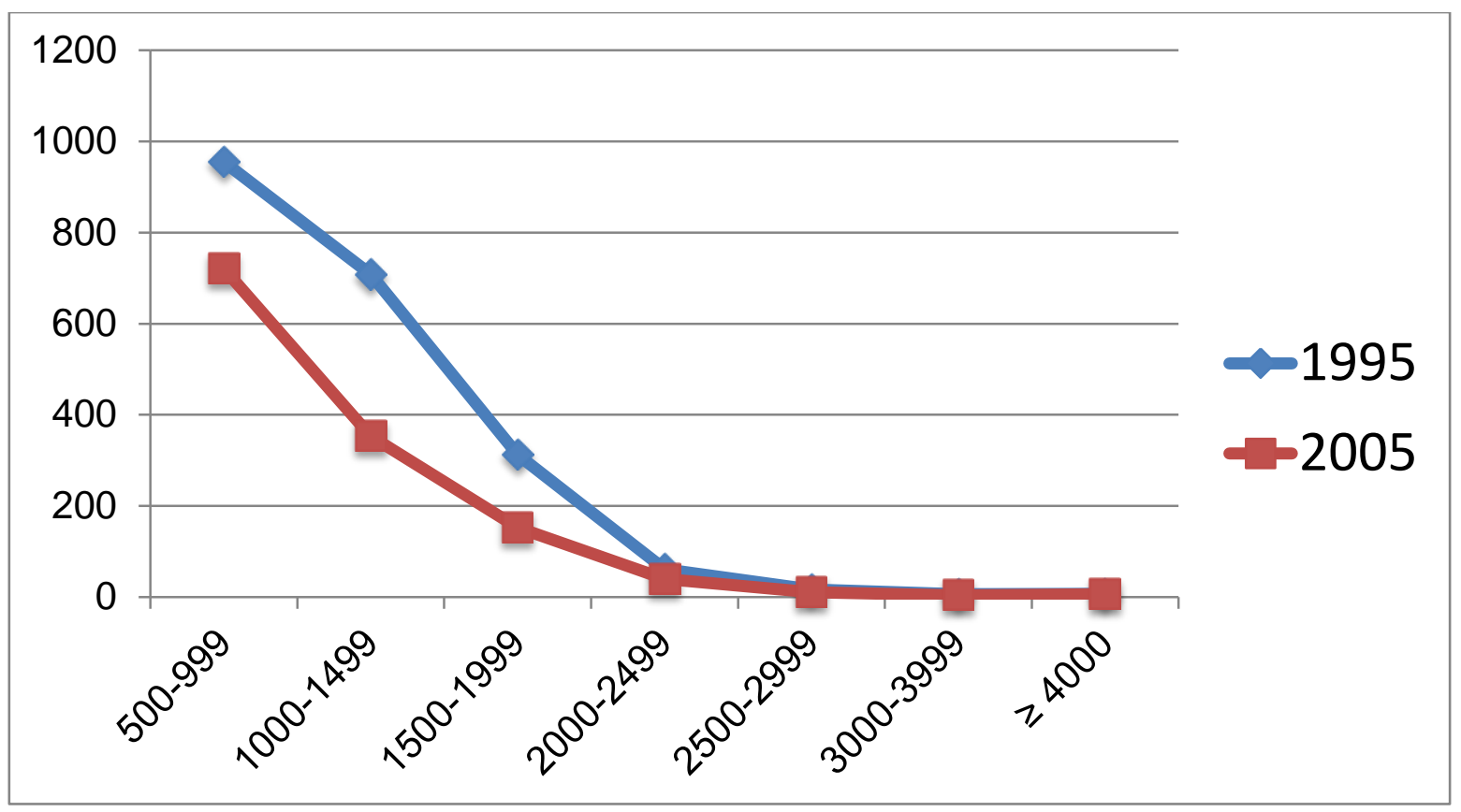

Quanto aos coeficientes de mortalidade fetal e sua relação com o peso ao nascer, não foram observadas reduções significativas no seu valor global, ao longo dos anos (Tabela 6).

Assim, como em 1995, os coeficientes de mortalidade fetal em 2005, ainda, foram expressivos entre os que se referem a peso menor de 1.000 gramas (408,4 por 1.000 nascimentos). Tal fato representa que os produtos de concepção com menos de $1.000 \mathrm{~g}$ tem uma estimativa de risco 55 vezes maior de ter sido uma perda fetal do que entre os nascimentos entre 2500 e 2999g.

Há de ser observada com cautela, em função do pequeno número de eventos, a evolução observada entre as perdas fetais na faixa de peso 3000 a 3999g, onde houve o maior declínio (50,0\%). 
Não há dúvida de que as reduções na mortalidade fetal foram importantes, com um decréscimo em geral de 19\%, entretanto, não foram tão expressivos como os observados entre os coeficientes de mortalidade perinatal e neonatal precoce (Tabelas 5 e 7).

Tabela 6 - Coeficientes de mortalidade fetal (por 1.000 nascimentos) segundo peso ao nascer (em gramas), em 1995 e 2005. Fortaleza-Ceará.

\begin{tabular}{c|rrc}
\hline Peso ao Nascer & \multicolumn{1}{|c}{1995} & 2005 & Redução \\
\hline 500 a 999 & 527,8 & 408,4 & 22,6 \\
1.000 a 1.499 & 287,6 & 211,2 & 26,5 \\
1.500 a 1.999 & 142,0 & 107,8 & 24,1 \\
2.000 a 2.499 & 37,2 & 31,9 & 14,2 \\
2.500 a 2.999 & 12,0 & 7,3 & 39,2 \\
3.000 a 3.999 & 4,4 & 2,2 & 50,0 \\
$\geq 4.000$ & 5,0 & 4,9 & 2,0 \\
\hline Total & 17,9 & 14,5 & 19,0 \\
\hline
\end{tabular}

Comparando os coeficientes de mortalidade hospitalar neonatal precoce nos dois anos, 1995 e 2005 (Tabela 7), foi possível observar que, dos indicadores aqui estudados, este apresentou a mais expressiva redução ao longo desses anos, com um decréscimo de 42,1\%, passando de 15,2 por mil nascidos vivos em 95, para 8,8 por mil nascidos vivos, em 2005.

Quando se distribuem os óbitos neonatais precoces nas faixas de peso ao nascer, percebe-se que houve queda em todas, principalmente, entre os recém nascidos com peso de 1.500 a 1.999g (cerca de $75 \%$ ).

Observando os valores para os nascidos com baixo peso, as chances de sobrevida ainda são precárias, principalmente para aqueles com peso de 
500 a 999g; eles apresentaram o maior coeficiente de mortalidade e o seu decréscimo, no período, foi mediano $(41,6 \%)$.

Tabela 7 - Coeficientes de mortalidade neonatal precoce hospitalar (por 1.000 nascidos vivos)segundo peso ao nascer (em gramas), em 1995 e 2005, Fortaleza-Ceará.

\begin{tabular}{c|rrc}
\hline Peso ao Nascer & \multicolumn{1}{|c}{1995} & \multicolumn{1}{c}{2005} & Redução \\
\hline 500 a 999 & 904,5 & 528,6 & 41,6 \\
1000 a 1499 & 593,6 & 179,7 & 69,7 \\
1500 a 1999 & 198,6 & 50,1 & 74,8 \\
2000 a 2499 & 24,3 & 7,7 & 68,3 \\
2500 a 2999 & 4,2 & 3,4 & 19,1 \\
3000 a 3999 & 2,1 & 1,8 & 14,3 \\
$\geq 4000$ & 1,8 & 1,6 & 11,1 \\
\hline Total & 15,2 & 8,8 & 42,1 \\
\hline \multicolumn{4}{r}{}
\end{tabular}

Quanto à mortalidade perinatal hospitalar segundo categorias de peso ao nascer, comparando nos dois anos estudados, foram observadas reduções de $35,2 \%, 38,4 \%$ e $32,9 \%$, respectivamente, nas categorias muito baixo peso, baixo peso e peso satisfatório, respectivamente (Tabela 8).

Pode-se perceber que entre os eventos de muito baixo peso ao nascer, a chance de morrer foi cerca de duas vezes maior que entre os de baixo peso ao nascer e 30,4 vezes maior entre estes, quando comparados com aqueles de peso maior ou igual a $2.500 \mathrm{~g}$. 
Tabela 8 - Coeficientes de mortalidade perinatal hospitalar (por 1000 nascimentos), segundo categorias de peso ao nascer, em 1995 e 2005. Fortaleza-Ceará.

\begin{tabular}{l|ccc}
\hline Categorias* & 1995 & 2005 & Variações (\%) \\
\hline Muito baixo & 821,1 & 532,2 & 35,2 \\
Baixo & 290,6 & 178,9 & 38,4 \\
Satisfatório & 8,5 & 5,7 & 32,9 \\
\hline Total & 32,8 & 23,3 & 29,0 \\
\hline
\end{tabular}

* Muito baixo: <1500g, Baixo: <2500g, Satisfatório: $\geq 2500 \mathrm{~g}$

Gráfico 3 - Coeficientes de mortalidade perinatal hospitalar(por 1000 nascimentos) segundo categorias de peso ao nascer, Fortaleza, 1995 e 2005.

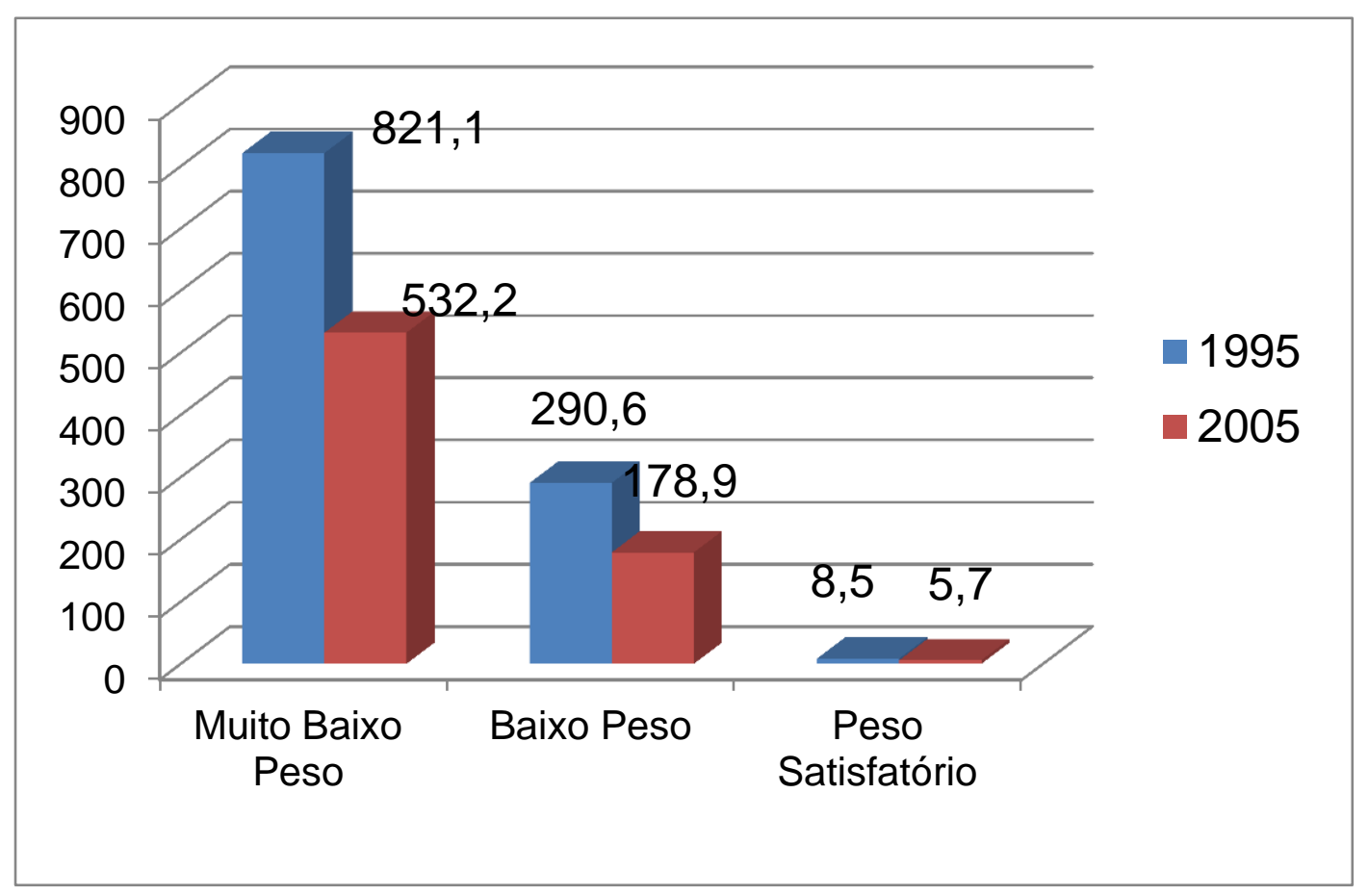

A evolução da mortalidade fetal hospitalar, quando comparada nos dois anos aponta redução importante $(42,6 \%)$ entre os óbitos fetais de peso 
satisfatório (Tabela 9). Em 2005, a estimativa do risco de ser uma perda fetal foi maior para as perdas com muito baixo peso (2,7 vezes a dos eventos de baixo peso). Já, nas perdas fetais com muito baixo peso, a estimativa do risco de morte foi cerca de 87 vezes maior do que aquelas de peso igual ou maior de $2.500 \mathrm{~g}$.

Tabela 9 - Coeficientes de mortalidade fetal hospitalar (por mil nascimentos) segundo categorias de peso ao nascer, em 1995 e 2005. Fortaleza-Ceará.

\begin{tabular}{l|rcc}
\hline Categorias & 1995 & 2005 & Variação (\%) \\
\hline Muito baixo & 397,8 & 307,2 & 22,7 \\
Baixo & 143,4 & 112,5 & 21,5 \\
Satisfatório & 6,1 & 3,5 & 42,3 \\
\hline Total & 17,9 & 14,5 & 18,9 \\
\hline
\end{tabular}

*Muito baixo: <1500g, Baixo: <2500g, Satisfatório: $\geq 2500 \mathrm{~g}$

Detectou-se uma expressiva redução $(56,4 \%)$ dos coeficientes de mortalidade neonatal precoce para as crianças nascidas em hospital e com baixo peso, em 1995 e em 2005 (Tabela 10). Neste último ano, o maior coeficiente de mortalidade neonatal precoce hospitalar foi apresentado pelo grupo de recém nascidos de muito baixo peso ao nascer $(324,7$ por 1.000 nascidos vivos) e a estimativa do risco de morte neste grupo de crianças foi 3,3 vezes maior relativamente à do grupo de baixo peso.

A mortalidade em menores de 7 dias de vida também é inversamente proporcional ao peso ao nascer, ao se compararem os recém nascidos com 
peso menor do que $2.500 \mathrm{~g}$ com aqueles de peso igual ou maior a $2.500 \mathrm{~g}$. Os primeiros estiveram expostos a um risco de morrer precocemente ao redor de 33 vezes maior do que a destes últimos.

Tabela 10 - Coeficientes de mortalidade neonatal precoce hospitalar (por 1.000 nascidos vivos) segundo categorias* do peso ao nascer, em 1995 e 2005. Fortaleza-Ceará.2010.

\begin{tabular}{l|ccc}
\hline Categorias* $^{*}$ & 1995 & 2005 & Redução $(\%)$ \\
\hline Muito baixo & 703,0 & 324,7 & 53,8 \\
Baixo & 171,8 & 74,8 & 56,5 \\
Satisfatório & 2,5 & 2,1 & 16,0 \\
\hline Total & 15,2 & 8,8 & 42,1 \\
\hline
\end{tabular}

*Muito baixo: <1500g, Baixo: <2500g, Satisfatório: $\geq 2500 \mathrm{~g}$

A ocorrência de nascidos vivos com muito baixo peso ao nascer (1,7\%), em 2005, aumentou 41,7\%, em relação à proporção de 1995. Quanto à mortalidade neonatal precoce proporcional também foi observado acréscimo de $7,5 \%$, entre 1995 e 2005 , de $57,3 \%$ para $61,7 \%$ e o coeficiente de mortalidade neonatal precoce hospitalar apresentou declínio $(53,8 \%)$, passando de 703 para 324,8 por mil nascidos vivos hospitalares de menos de $1500 \mathrm{~g}$ (Tabela 11). 
Tabela 11 - Proporção de nascidos vivos de muito baixo peso ao nascer (\%) e mortalidade neonatal precoce hospitalar (\%) e coeficiente de mortalidade neonatal precoce hospitalar (por 1.000 nascidos vivos de muito baixo peso) em 1995 e 2005, Fortaleza, Ceará.

\begin{tabular}{l|ccc}
\hline \multicolumn{1}{c|}{ Indicadores } & 1995 & 2005 & Variação (\%) \\
\hline Proporção de NV (\%) & 1,2 & 1,7 & $+41,7$ \\
Mort. Neo. Precoce (\%) & 57,3 & 61,7 & $+7,5$ \\
C. Mort. Neon. Prec. (\%o NV) & 703,0 & 324,8 & $-53,8$ \\
\hline
\end{tabular}

Foi verificado aumento na ocorrência de recém nascidos de peso menor de $2500 \mathrm{~g}$, da ordem de $23 \%$. Quanto à proporção de mortes neonatais precoces de baixo peso, houve decréscimo, assim como com o coeficiente de mortalidade neonatal precoce que apresentou redução de $56,7 \%$ (Tabela12).

Tabela 12 - Proporção de nascidos vivos de baixo peso (\%), mortalidade neonatal precoce hospitalar (\%) e coeficiente de mortalidade neonatal precoce hospitalar (por 1.000 nascidos vivos de baixo peso)em 1995 e 2005, Fortaleza, Ceará.

\begin{tabular}{l|ccc}
\hline \multicolumn{1}{c|}{ Indicadores } & 1995 & 2005 & Variação (\%) \\
\hline Proporção de NV (\%) & 7,4 & 9,1 & $+23,0$ \\
Mort. Neo. Precoce (\%) & 83,6 & 77,4 & $-7,4$ \\
Coef. Mort. Neonatal & 171,8 & 74,9 & $-56,4$ \\
Precoce (\%o NV no peso) & & & \\
\hline
\end{tabular}

A evolução na ocorrência de nascidos vivos com peso insuficiente apresentou acréscimo entre os dois anos; passando de 19,5\%, em 1995, para $21,1 \%$ em 2005 . Houve ainda aumento na proporção de óbitos nesta faixa de peso, com acréscimo relativo, entre os dois anos, de $51,9 \%$ e 
redução no coeficiente de mortalidade neonatal precoce de 19,0\% (Tabela 13).

Tabela 13 - Nascidos vivos de peso insuficiente ao nascer (\%) e respectivos mortalidade neonatal precoce hospitalar (\%) e coeficiente de mortalidade neonatal precoce hospitalar (por 1.000 nascidos vivos de peso insuficiente), em 1995 e 2005, Fortaleza, Ceará.

\begin{tabular}{l|ccc}
\hline \multicolumn{1}{c|}{ Indicadores } & 1995 & 2005 & Variação \% \\
\hline Ocorrência de nascidos vivos no peso (\%) & 19,5 & 21,1 & $+8,2$ \\
Mortalidade Neonatal Precoce (\%) & 5,4 & 8,2 & $+51,9$ \\
C. Mort. Neonatal Prec. (\%o NV no peso) & 4,2 & 3,4 & $-19,0$ \\
\hline
\end{tabular}

A ocorrência de nascidos vivos com peso de $3000 \mathrm{~g}$ ou mais apresentou tendência de queda entre os dois anos $(1,7 \%)$, assim como o coeficiente de mortalidade neonatal, com $12 \%$ de redução. A proporção de mortes neste grupo de peso aumentou entre os dois anos para $45,8 \%$ (Tabela 14).

Tabela 14 - Proporção dos nascidos vivos de peso satisfatório ao nascer (\%) e respectivos mortalidade neonatal precoce hospitalar (\%) e Coeficiente de mortalidade neonatal precoce hospitalar (por 1.000 nascidos vivos de peso satisfatório), em 1995 e 2005, Fortaleza, Ceará.

\begin{tabular}{l|rrc}
\hline \multicolumn{1}{c|}{ Indicadores } & 1995 & 2005 & $\begin{array}{c}\text { Variação } \\
(\%)\end{array}$ \\
\hline \multicolumn{1}{c|}{ Ocorrência (\%) } & 92,5 & 90,9 & $-1,7$ \\
Mortalid. Neonatal Precoce (\%) & 15,5 & 22,6 & $+45,8$ \\
$\begin{array}{l}\text { Coef. Mort. Neonatal Precoce } \\
\text { (\%o NV de peso satisfatório) }\end{array}$ & 2,5 & 2,2 & $-12,0$ \\
\hline
\end{tabular}


Tabela 15 - Proporção (\%) de cesáreas de acordo com os hospitaismaternidades em 1995 e 2005. Fortaleza-Ceará.

\begin{tabular}{|c|c|c|c|}
\hline Hospital Público & 1995 & 2005 & $\begin{array}{c}\text { Variação } \\
\%\end{array}$ \\
\hline $\begin{array}{l}\text { 1.Maternidade Escola Assis } \\
\text { Chateaubriand }\end{array}$ & 29,0 & 47,7 & $+64,5$ \\
\hline $\begin{array}{l}\text { 4. Hospital N. Senhora da } \\
\text { Conceicão* } \\
5 . \text { Hospital Gonzaguinha } \\
\text { Messeiana } \\
\text { 6. Hospital Gonzaguinha }\end{array}$ & ------ & 48,5 & $\begin{array}{l}------ \\
+259,3 \\
-40,6\end{array}$ \\
\hline 7.Hospital Gonzaguinha & & 34,9 & $+60,0$ \\
\hline 8. Hospital Fernandes Távora & 16,6 & 25,4 & $+53,0$ \\
\hline 9. Hospital Juvenal Carvalho & & & $+42,5$ \\
\hline 10.Hospital Menino Jesus & & & $+103,5$ \\
\hline $\begin{array}{l}\text { 11. Hospital Arg.Castelo } \\
\text { Branco } \\
\text { 12. Hospital Batista }\end{array}$ & 35,3 & 50,3 & $\begin{array}{l}+85,4 \\
-11,0\end{array}$ \\
\hline Hospital Cura'Dars & 11,3 & 23,0 & $+12,7$ \\
\hline $\begin{array}{l}\text { 13. Hospital Angeline }{ }^{* *} \\
\text { 14.Policlínica****}\end{array}$ & ------ & 68,3 & -------- \\
\hline $\begin{array}{l}\text { 15. Hospital Gomes da } \\
\text { Frota***** }^{*} \text { 16.H.Arrumadores }{ }^{\star * \star *}\end{array}$ & 49,6 & -------- & -------- \\
\hline 17.C.S.São Pedro*** & & & --------- \\
\hline $\begin{array}{l}\text { 18. Hospital São } \\
\text { Raimundo***** }\end{array}$ & 36,0 & -------- & --------- \\
\hline Total & 30,5 & 39,9 & 30,8 \\
\hline
\end{tabular}

*Hospital não existia em 1995

** Hospital não participou do estudo em 1995

****Hospital não existe mais

***** Hospital em 2005 não fazia mais atendimento perinatal 
Pode ser observada em 2005 uma redução na mortalidade perinatal de $54,4 \%$ quando comparado com 1995 (Tabela 16).

Houve reduções em todas as faixas de idade, quando comparados os dois anos, chamando atenção para o comportamento da mortalidade perinatal na faixa de idade de 15 a 19 anos, que diminuiu mais da metade $62,1 \%$ e entre as adolescentes de modo geral, que apresentou decréscimo de $60,5 \%$ (Tabela 16).

Tabela 16. Coeficientes da mortalidade perinatal segundo a idade materna (por 1000 nascimentos) em 1995 e 2005 em Fortaleza-Ceará.

\begin{tabular}{c|c|c|c}
\hline Idade da Mãe (em anos) & \multicolumn{1}{|c|}{1995} & 2005 & Variação (\%) \\
\hline 10 a 14 & 37,7 & 29,9 & $-20,6$ \\
15 a 19 & 37,3 & 14,1 & $-62,1$ \\
Total de Adolescentes & 37,3 & 14,7 & $-60,5$ \\
\hline 20 a 34 & 29,7 & 13,6 & $-54,2$ \\
35 ou mais & 44,1 & 26,3 & $-40,3$ \\
Total de Adultas & 31,1 & 15,1 & $-51,4$ \\
\hline Total & 32,8 & 15,0 & $-54,2$ \\
\hline
\end{tabular}

Quanto à variação da mortalidade fetal segundo a idade materna, observa-se que, apesar de terem ocorrido reduções em todas as faixas etárias, quando comparadas com a mortalidade perinatal e neonatal precoce, estas foram bem inferiores. A mortalidade fetal segundo a idade da mãe passou de 17,9 por 1000 nascimentos em 1995 para 15 por 1000 nascimentos em 2005, reduzindo $16,2 \%$ (Tabela 18). 
Chama-se atenção para o aumento das mortes fetais entre mães de 10 a 14 anos, igual a $137,3 \%$ (Tabela 17$)$.

Tabela 17. Coeficientes da mortalidade fetal segundo a idade materna (por 1000 nascimentos ) em 1995 e 2005 em Fortaleza-Ceará.

\begin{tabular}{c|c|c|c}
\hline Idade da Mãe (em anos) & 1995 & 2005 & Variação (\%) \\
\hline 10 a 14 & 12,6 & 29,9 & $+137,3$ \\
15 a 19 & 17,4 & 14,1 & $-18,9$ \\
\hline Total de Adolescentes & 17,1 & 14,7 & $-14,0$ \\
\hline 20 a 34 & 16,7 & 13,6 & $-18,5$ \\
35 ou mais & 28,0 & 26,3 & $-6,0$ \\
Total de Adultas & 17,8 & 15,1 & $-15,2$ \\
\hline Total & 17,9 & 15,0 & $-16,2$ \\
\hline
\end{tabular}

Observa-se redução importante da mortalidade neonatal precoce, para os nascidos vivos de quaisquer faixas de idade materna, principalmente, entre produtos de mães de 10 a 14 anos, cujo coeficiente passou de 25,5 por 1.000 nascidos vivos, em 1995, para 15,4 por 1.000 nascidos vivos, em 2005, reduzindo em 65,5\%(Tabela 18).

A redução das mortes neonatais precoces foi maior entre nascidos vivos de mães adolescentes $(50,9 \%)$ do que entre os de mães adultas $(36,8 \%)$ (Tabela 18). 
Tabela 18. Coeficientes de mortalidade neonatal precoce de acordo com idade materna (por 1000 nascimentos) entre 1995 e 2005. Fortaleza,

\begin{tabular}{c|c|c|c}
\hline Idade da Mãe (em anos) & 1995 & 2005 & Variação (\%) \\
\hline 10 a 14 & 25,5 & 15,4 & $-65,5$ \\
15 a 19 & 20,2 & 9,8 & $-51,4$ \\
Total de Adolescentes & 20,4 & 10,0 & $-50,9$ \\
\hline 20 a 34 & 13,1 & 9,1 & $-30,5$ \\
35 ou mais & 16,5 & 11.8 & $-28,4$ \\
Total de Adultas & 13,5 & 9,4 & $-30,3$ \\
\hline Total & 15,2 & 9,6 & $-36,8$ \\
\hline
\end{tabular}




\section{DISCUSSÃO DOS RESULTADOS}

\section{ASPECTOS DA ORGANIZAÇÃO DA ATENÇÃo PERINATAL DE}

FORTALEZA

Após dez anos do estudo da mortalidade perinatal no município de Fortaleza, realizado em 1995, que permitiu evidenciar uma situação precária da saúde perinatal, outra pesquisa foi realizada, em 2005, para estimar e comparar os valores dos novos indicadores, em face da implementação das principais mudanças ocorridas na atenção prestada à mulher grávida e ao seu produto de gestação.

Durante o decênio, foram realizados vários investimentos nesta área específica, incluindo decisões precisas e oportunas na área de gestão. Ações estas responsáveis por grande transformação no cenário hospitalar da rede pública e da rede conveniada com o SUS, na capital, responsáveis por aproximadamente $85 \%$ dos partos.

Em 1995, alguns anos após a criação do Sistema Único de Saúde SUS - no Brasil, responsável pelas ações e serviços de saúde prestados à população, era comum, em Fortaleza, a compra de serviços do setor privado, pelo setor público, sendo a grande maioria das instituições de baixa complexidade e de alta rentabilidade.

Com a reorganização da atenção hospitalar, pode-se perceber o fortalecimento dos hospitais públicos no atendimento perinatal. Houve 
ampliação do número de leitos de obstetrícia e neonatalogia, nos principais centros de referência. Nesta área de atenção, foram ações importantes a aquisição de novos leitos de terapia intensiva neonatal, além de investimentos tecnológicos de elevado impacto na sobrevivência de recém nascidos de alto risco. Por outro lado, foram oferecidos incentivos para a qualificação de profissionais de saúde, como cursos de pós-graduação latu e strictu senso e cursos de capacitação em reanimação neonatal.

Em relação à atenção primária na capital, somente em 1998 foram implantadas as primeiras 32 equipes do Programa Saúde da Família - PSF -, que foi ampliada, em 2000, para 109 equipes, distribuídas nas seis Secretarias Executivas Regionais-SER. ${ }^{36}$ Este acréscimo certamente deve ter contribuído para a maior cobertura da atenção pré-natal, desde 1999, em Fortaleza.

Segundo dados da Secretaria de Saúde de Fortaleza, em relação às 15.967 declarações de nascidos vivos (DN) emitidas em 1999, a cobertura da atenção de pré-natal com sete ou mais consultas foi igual a 60\% (9.589 DN), a realização de nenhuma consulta foi informada em 643 DN (4\%) e 36\%(5735 DN) notificaram número ignorado de consultas ou o item não estava preenchido. Nos anos seguintes, com o aumento da cobertura do SINASC na capital, foi possível verificar aprimoramento da atenção prénatal. $^{36}$

Os recursos aplicados na atenção primária, para a melhoria do prénatal, refletem-se significativamente nos valores dos indicadores de saúde perinatal. $^{37}$ 
A importância do pré-natal como fator de proteção à saúde da mulher grávida, do feto e do recém nascido, é apontada por autores, além da sua contribuição na redução das mortes maternas e na incidência do baixo peso ao nascer, melhorando os valores dos indicadores perinatais. ${ }^{38}$

Quanto ao PSF, os estudos reforçam seu papel fundamental na captação de gestantes, favorecendo o elo entre o serviço de saúde e a comunidade, reforçando o vínculo e a confiança da mulher grávida com o serviço. Tal fato repercute diretamente na aceitação dos cuidados pré, peri e pós-natais e daqueles direcionados à criança, nos dois primeiros anos de vida, feitos pelas unidades de saúde (SANTOS, 2009).

Em 1995, os hospitais conveniados responsabilizaram-se por $67,6 \%$ dos partos, enquanto que aos hospitais públicos corresponderam $32,4 \%$ deles. Vale ressaltar que na ocasião, nos 17 hospitais (cinco públicos e 12 conveniados com o SUS), ocorreram $85 \%$ dos partos da capital. ${ }^{8}$

Um fato importante a ser ressaltado foi a pouca participação dos três hospitais distritais, em 1995, que juntos contabilizaram apenas 3.260 partos, correspondendo a $8 \%$ do total de nascimentos hospitalares do ano.

Após 1995, estes hospitais passaram por mudanças organizacionais. Houve investimentos em recursos humanos, tecnológicos e estruturais que envolveram ampliação e aquisição de novos leitos destinados à mulher grávida e ao recém nascido, capacitando-os à condição de referência secundária, na atenção perinatal. Foram, em 2005, responsáveis por $28 \%$ dos partos de residentes na região metropolitana de Fortaleza, representando um total de atendimentos 3,5 vezes ao de 1995 (Tabela 1). 
O fortalecimento dos hospitais públicos pode ser constatado na comparação do total de partos nos dois anos de referência. Nestas instituições, houve aumento de $66,5 \%$ no número de partos, isto é, de $13.208(32,4 \%)$, em 1995, para $21.989(71,7 \%)$, em 2005. O aumento relativo de cobertura foi igual a $121 \%$.

Vale ressaltar que os dois hospitais vinculados à rede estadual e que são referência terciária, também, passaram a ter maior participação na atenção à mulher grávida e ao recém nascido. Assim, houve aumento da proporção de partos de 14,7\%, em 1995, para 19,8\%, em 2005. Este incremento de 34,7\% na participação deve-se à ampliação do número de leitos obstétricos.

Quanto ao Centro Perinatal de Referência Terciária, do Ministério da Saúde, apesar de ser o local onde ocorreu o maior número de nascimentos, em 2005, ao ser comparado aos dados de 1995, decresceu de 7.197 (em 1995) para 4.376 partos, em 2005, o que aponta redução de 39,2\% (Tabela 1).

Esta redução de quase $40 \%$ no total de partos nesta maternidade pode estar associada à criação de novos leitos para a atenção perinatal nos dois hospitais estaduais, dividindo a demanda, inclusive por serem instituições com as mesmas características de atendimento.

Nos hospitais conveniados com o SUS, o número de partos diminuiu de 27.504 (2/3 do total de partos em 1995), para 8.689 (28,3\% em 2005), com um decréscimo de partos de 68,4\% (Tabela 1). Outro dado importante, a ser comentado, é que dos onze hospitais conveniados com o SUS 
participantes do estudo de 1995, apenas sete fizeram parte da pesquisa de 2005.

Ao se compararem os indicadores dos hospitais públicos, em 1995 e 2005, foram verificados decréscimos nos valores dos coeficientes de mortalidade; assim o de mortalidade perinatal hospitalar diminuiu em 57,7\%, o de mortalidade fetal hospitalar, em $50,4 \%$ e o de mortalidade neonatal precoce decresceu em 66,3\% (Tabela 18). Esta redução sugere haver, possivelmente, melhores condições de atendimento tanto à gestante como ao recém nascido, nos primeiros dias de vida, por terem sido agregados, aos serviços, investimentos, sofisticados tecnologias de saúde e recursos humanos mais capacitados.

Um estudo sobre avaliação de hospitais que prestam assistência perinatal em Belo Horizonte ressalta que as condições hospitalares têm uma relação direta com a condição de sobrevivência dos recém nascidos. Assim, situações desfavoráveis são prejudiciais, podendo levá-los à morte. Os autores ainda ressaltam que o óbito do RN de baixo peso deixa de estar associado à assistência pré-natal e passa a ser dependente da qualidade do atendimento hospitalar. $^{39}$

As estatísticas dos hospitais conveniados, comparadas nos dois momentos, apresentaram menor redução nos indicadores perinatais, comparativamente aos hospitais púbicos; assim, o coeficiente de mortalidade perinatal hospitalar decresceu $18,3 \%$, o de mortalidade fetal, $7,7 \%$ e o de mortalidade neonatal precoce diminuiu em $38,5 \%$. Vale ressaltar que, mesmo sendo hospitais de baixa complexidade para a 
atenção à gestante e ao recém nascido, sem competência clínica e tecnológica para enfrentar situações que indicam risco para o binômio, os coeficientes ainda assim permaneceram muito elevados.

A existência de padrões técnicos mínimos para a provisão de atendimento perinatal e neonatal é garantida pelos programas de acreditação hospitalar e já fazem parte da maioria dos hospitais americanos, canadenses e australianos. É provável que possa ser alcançada uma redução da mortalidade perinatal em até $25 \%$, se forem asseguradas condições favoráveis de atenção hospitalar à mulher grávida e ao seu produto de concepção. ${ }^{39}$

Em Fortaleza pode-se observar melhorias nos hospitais públicos de atendimento perinatal. As aquisições foram voltadas para as unidades de atenção à mulher grávida e principalmente para as unidades de terapia intensiva, com vistas nas certificações/ programas de acreditação hospitalar. Dos hospitais públicos que participaram do estudo de 2005, quatro foram preparados para as visitas de acreditação.

Apesar de ter havido importantes transformações favoráveis no cenário da saúde perinatal, em Fortaleza, ao longo destes dez anos, os indicadores apontam uma situação ainda plena de obstáculos a serem vencidos. Não há dúvida que os hospitais da rede pública vêm melhorando seus atendimentos, disponibilizando recursos humanos preparados e habilitados para a aplicação de novas tecnologias, visando à sobrevida dos nascidos prematuros e de baixo peso; entretanto, evidenciam-se, ainda, 
muitas dificuldades e falhas que os distanciam do alcance da excelência na qualidade da atenção.

Observa-se grande concentração de unidades de terapia intensiva neonatais (UTI) na capital; mas, a metade das crianças internadas nas UTI é procedente do interior do estado ou de municípios que não disponibilizam políticas, programas e nem recursos para este tipo de atenção. A inexistência de leitos ocasiona períodos de superlotação e conseqüentemente prejuízo para a segurança e qualidade do atendimento prestado. Outro fato importante e muito comum é a busca de atendimento de referência pelas gestantes vindas do interior. Elas arriscam muitas vezes uma peregrinação por várias maternidades, aumentando o risco de morte tanto para elas como para o RN. O transporte neonatal é uma preocupação e tem sido assunto em discussão, principalmente, nos aspectos relacionados com a qualidade do seu funcionamento seguro.

Há problemas relacionados ao acesso devido à oferta insuficiente de serviços de alta e média complexidade, além, das dificuldades na gestão de recursos humanos. Estes problemas são mencionados por autores ao analisarem-se as reais chances de sobrevida de recém nascidos extremamente pequenos, nos serviços perinatais do país. Eles apontaram em seu estudo, que persiste a falta de uniformidade nos cuidados necessários, assim como a pouca confiabilidade dos prontuários relatando a utilização dos serviços. ${ }^{40}$

Um estudo sobre recém nascidos com peso inferior a $1500 \mathrm{~g}$, produtos de partos ocorridos em Fortaleza, em 2002, evidenciou uma 
mortalidade hospitalar elevada para todas as faixas de peso ao nascer, tendo a maioria das mortes ocorrida na primeira semana de vida. Os altos coeficientes de mortalidade hospitalar neste grupo específico sugerem falhas com a prestação dos cuidados nas UTI neonatais. ${ }^{41}$

São muitos os desafios a enfrentar no âmbito perinatal no Brasil, principalmente, nos locais onde há obstáculos para o alcance dos avanços. Urge a necessidade da organização da rede de assistência à mulher grávida e ao recém nascido, que integre os serviços desde o pré-natal, trabalho de parto, parto, assistência ao recém nascido, planejamento familiar até a puericultura. Esta rede deve ser resolutiva, capaz de efetuar ações de promoção à saúde, prevenção dos agravos e redução das mortes evitáveis de mulheres e de seus conceptos.

\section{A SITUAÇÃO DOS INDICADORES PERINATAISDE FORTALEZA EM DOIS MOMENTOS - 1995 e 2005}

A análise comparativa dos indicadores de saúde perinatal de Fortaleza, em 1995 e 2005, aponta para mudanças nos coeficientes de mortalidade perinatal, fetal e neonatal precoce. As reduções podem estar associadas aos avanços que ocorreram na atenção de saúde de mulheres grávidas e de seus recém nascidos no município, por todos estes anos.

Estudos reforçam a importância da mortalidade perinatal na compreensão dos problemas da assistência prestada à gestante, ao feto e ao recém nascido nos primeiros dias de vida, relacionando-os com possíveis falhas na atenção durante a gravidez, parto e pós-parto. ${ }^{35,42}$ 
É tema ainda relevante para estudá-lo como um importante evento em saúde pública, conhecendo desta forma sua magnitude, seus determinantes e suas tendências temporais, na busca de intervenções apropriadas para sua significativa redução. ${ }^{42,43}$

Valores elevados de óbitos perinatais ocorrem em países onde as condições de vida da população são mais precárias e desfavorecidas. A incidência média dessas mortes nos países pobres é de 60 por mil nascimentos, sendo as chances de morte cerca de seis vezes maiores nestes países quando comparados com os desenvolvidos. ${ }^{39,44,45}$

Os avanços na oferta e na prestação de atendimento à gestante em todo curso da gravidez, trabalho de parto e parto, e aos recém nascidos, foram investimentos importantes e que possibilitaram o declínio das mortes perinatais ao longo de todos estes anos, nos países mais desenvolvidos.

Em Fortaleza, também com investimentos nesta área específica, foi possível detectar redução de $29 \%$ entre os coeficientes de mortalidade hospitalar perinatal de 1995 e de 2005, respectivamente, 32,5 e 23,3 por mil nascimentos (Tabela 5).

Apesar do declínio de cerca de 30\%, comparativamente com Belo Horizonte (MG) e Rio de Janeiro (RJ), Fortaleza ainda apresenta coeficiente de mortalidade perinatal mais elevado $10 \%$ e $28,7 \%$, respectivamente. ${ }^{46,47}$

Outro estudo de base populacional realizado em Curitiba, em 2005, mostrou 0 coeficiente de mortalidade perinatal de 11,9 por 1000 nascimentos, valor este $49 \%$ inferior ao de Fortaleza, no mesmo ano. ${ }^{45}$ 
De acordo com dados da Rede Interagencial de Informações para a Saúde-RIPSA, a mortalidade perinatal em alguns estados brasileiros teve tendência de queda, de 1997 a 2004. Assim, os estados do Rio Grande do Sul, Santa Catarina, Rio de Janeiro e São Paulo conseguiram alcançar reduções importantes de 8,0\%, 11,8\%, 23,4\%, 15,7\% respectivamente.

Estudo de base populacional realizado na cidade do Recife, no período de 2000 a 2004, estimou mortalidade perinatal de 21,3/1000 nascimentos; em Fortaleza; em 2005, o nível foi 8,5\% mais elevado. ${ }^{48}$

Nos países desenvolvidos, as mortes perinatais vêm apresentando tendência de declínio, com coeficientes expressivamente inferiores em relação aos de cidades brasileiras. No ano 2000, os Estados Unidos da America apresentaram coeficiente de mortalidade perinatal de 6,8 por 1000 , o Reino Unido de 8 por 1000 e o de Japão 7 por 1000 nascimentos. ${ }^{49}$

Em relação à mortalidade fetal, que abrange todos os óbitos fetais a partir da $22^{a}$ semana de gestação, apresentou um decréscimo de 18,9\% para todas as faixas de peso ao nascer, nos dez anos, reduzindo de 17,9 por 1000 para 14,5 por 1000 nascimentos.

Quanto ao peso ao nascer, sabe-se que as chances de sobrevivência aumentam proporcionalmente à medida que ele também aumenta, além de ser uma variável utilizada para definição de perda fetal, quando é desconhecida a idade gestacional. ${ }^{11,41}$

O que se pode observar quanto às mortes fetais nos dois momentos, é que a faixa ponderal que obteve maior redução foi a de fetos com 3000 a $3999 \mathrm{~g}$ e aqueles com 2.500 a $2.999 \mathrm{~g}(54,5 \%$ e $39,2 \%$ respectivamente). 
Número elevado de óbitos fetais de peso no mínimo igual a $2500 \mathrm{~g}$ pode estar relacionado a problemas na identificação de riscos apresentados pela mulher grávida, no período em que o feto encontra-se próximo da máxima vulnerabilidade, além de falhas na atenção perinatal, obrigando-a peregrinar em busca de assistência hospitalar nas horas que antecedem o parto. ${ }^{35,47}$

Em relação às perdas fetais com peso inferior a $1500 \mathrm{~g}$, para todas elas observou-se redução, sendo $26,5 \%$, para a faixa de1000 a $1499 \mathrm{~g}$.(muito baixo peso ao nascer) e a menor queda entre os conceptos com extremo baixo peso ao nascer, isto é, os menores de $1.000 \mathrm{~g}(22,6 \%)$.

O pequeno declínio detectado nos menores de $1.000 \mathrm{~g}$, no passar dos dez anos, sugere problemas no pré-natal, na identificação precoce dos riscos, como, também, nas suas próprias condições insatisfatórias condicionadas pelo extremo baixo peso.

Em países desenvolvidos, há uma maior concentração dos óbitos fetais entre conceptos menores de $1500 \mathrm{~g}$ em detrimento dos que pesam no mínimo $2500 \mathrm{~g}$, devido à melhor prestação de serviços perinatais. ${ }^{45}$

Nos Estados Unidos, o coeficiente de mortalidade fetal entre 2000 e 2004 foi igual a 4,12 por 1.000 nascimentos, com maior concentração destas perdas no período fetal precoce, que compreende os óbitos de conceptos com 20 a 27 semanas de gestação. No Japão, Reino Unido e Canadá, em 2006, os valores foram, respectivamente, 2,5 por mil nascimentos, 5,3 e 3,2 por mil nascimentos. ${ }^{50}$ 
Relacionando-se a esses dados, observa-se que o índice de perdas fetais, em Fortaleza, foi aproximadamente três vezes mais elevado que o americano, seis vezes maior que o do Japão, o triplo do Reino Unido e quase cinco vezes o do Canadá.

Em São Paulo, em 2006, a mortalidade fetal foi de sete por mil nascimentos, sendo a maior parte destes óbitos de conceptos com peso inferior a $1.000 \mathrm{~g}$. Quando comparada com a mortalidade fetal da cidade de São Paulo, em 2005, a de Fortaleza apresentou-se mais elevada $(51,0 \%)$ e também com maior concentração de perdas entre menores de $1.000 \mathrm{~g} .{ }^{44}$

Estudos reforçam a importância do acesso ampliado aos serviços de atenção perinatal regionalizados, como estratégia utilizada por países desenvolvidos para uma efetiva redução das mortes perinatais. Existem evidências que o grande declínio observado nos Estados Unidos na década de setenta ocorreu graças a este tipo de intervenção. ${ }^{51}$

Vários estudos apontam a asfixia como principal causa básica da morte fetal, especialmente aquelas que ocorrem nas últimas semanas de gravidez. Nos países mais desenvolvidos, com o melhor monitoramento e com os aprimoramentos na assistência durante o trabalho de parto e parto, o coeficiente de óbito fetal reduziu significativamente. ${ }^{51}$

Quanto aos países mais pobres, percebe-se ainda uma desorganização do atendimento à mulher grávida, com maior concentração dos serviços em áreas que não contemplam a população mais necessitada, fato que acentua ainda mais as desigualdades sociais nestes locais. ${ }^{53}$ 
No caso de Fortaleza, não diferente do cenário brasileiro, iniciativas que enfatizam a regionalização da assistência perinatal, como estratégia para reduzir as mortes neste período, ainda são incipientes, apesar dos esforços coletivos das Secretarias de Saúde municipal e estadual, principalmente, com a criação de leitos de terapia intensiva neonatal e de médio risco. Entretanto, ainda persiste o desafio na redução da mortalidade perinatal, acompanhando as tendências e os padrões de saúde de áreas mais desenvolvidas.

No tocante à mortalidade neonatal precoce, cada vez mais, estudos reforçam sua relação negativa com peso ao nascer e idade gestacional, aumentando à medida que decrescem estas duas variáveis.

No entanto, a gestão de cuidados cada vez mais avançados, com tecnologias de última geração sendo utilizadas, nas unidades de tratamento intensivo, aliadas à melhor formação dos profissionais, tem sido possível aumentar a sobrevida de crianças que antes morriam muito precocemente.

Dos três coeficientes estudados, a mortalidade neonatal precoce foi a que mais se reduziu, nos dez anos, passando de 15,2 para 8,2 por 1.000 nascidos vivos, com declínio de $42 \%$. Reduções importantes foram observadas em nascidos de todas as faixas de peso, com ênfase naqueles de muito baixo peso e de extremo baixo peso, respectivamente, $69,7 \%$ e $41,6 \%$.

No Brasil, o declínio da mortalidade neonatal precoce tem sido observado em todas as regiões, sendo mais acentuado nas regiões Sul e 
Sudeste, com valores de 7,4 e 7,6 por 1.000 nascidos vivos. As demais regiões, apesar de terem conseguido diminuir o número de mortes na primeira semana de vida, ainda possuem altos índices, quando comparados com os do Sul e Sudeste. No Nordeste, este coeficiente é 2,3 vezes maior que o observado na região Sul. ${ }^{52}$

As mortes no período neonatal precoce correspondem a mais da metade das mortes de menores de um ano, em todas as regiões brasileiras. Assim, têm- se constituído em um grande desafio sua redução, visto que requerem estratégias específicas, envolvendo medidas que garantam qualidade durante todo o ciclo gravídico e na atenção na sala de parto. ${ }^{35}$

Apesar da redução observada nas mortes neonatais precoces em Fortaleza, entre 1995 e 2005, constata-se que ainda apresentam valores elevados, quando comparadas com as capitais do Sul e Sudeste. Curitiba no mesmo ano apresentou coeficiente de 5,7 por mil nascidos vivos e em São Paulo, em 2006, este índice foi de 5,6 por mil nascidos vivos. Em relação à Curitiba, a mortalidade neonatal precoce em Fortaleza está 35\% mais elevada, e, relativamente ao coeficiente de São Paulo, está 37\%maior. ${ }^{44,45}$

Estudos enfatizam que a redução dos óbitos neonatais em países mais desenvolvidos tem relação com a melhor utilização das tecnologias neonatais. Uma pesquisa realizada nos Estados Unidos apontou o risco 82\% menor de óbito neonatal, diante da utilização de corticóideantenatal em mulheres com 23 semanas de gestação. As mortes por hemorragia 
intraventricular e por enterocolite necrotizante foram as que mais se reduziram entre os recém nascidos extremamente prematuros. ${ }^{41}$

Já são esperados melhores indicadores em países mais ricos, visto que a oferta de serviços e o acesso são melhores em detrimento dos países mais pobres. As precárias condições da assistência à saúde perinatal tem como conseqüência uma proporção maior de nascimentos prematuros que é o principal determinante da morbi-mortalidade neonatal nos países em desenvolvimento. ${ }^{54}$

Estudo realizado em unidades neonatais de hospitais universitários, nos estados do Rio de Janeiro, São Paulo e Rio Grande do Sul, concluiu que embora sendo instituições de referência para o atendimento de recém nascidos de alto risco e contando com recursos tecnológicos e recursos humanos para a assistência intensiva, de acordo com as normas do Ministério da Saúde, a mortalidade neonatal precoce hospitalar foi elevada, quando comparada com o padrão dos países desenvolvidos. Os autores reforçam a "otimização" na utilização tanto de corticóides ante-natal quanto dos surfactantes após o nascimento, como ações para diminuir a gravidade da síndrome do desconforto respiratório e, até mesmo, a sua incidência, pois é um importante fator de risco associado ao óbito neonatal precoce. ${ }^{54}$

Resultados semelhantes foram encontrados em uma coorte hospitalar realizada em 2002 em Fortaleza, com recém nascidos de muito baixo peso ao nascer $(<1500 \mathrm{~g})$. A mortalidade neonatal precoce foi de 335 por 1.000 nascidos vivos, sendo 2,4 vezes maior que a tardia, com uma redução de 
$3,2 \%$ entre os anos de 2002 e 2005. Os autores aventaram uma deficiência na assistência intensiva neonatal nos hospitais e desorganização do processo de atenção a estes recém nascidos, apesar da disponibilidade de recursos tecnológicos suficientes nas unidades de Fortaleza. ${ }^{41}$

Em relação ao peso ao nascer, pode-se observar mudança nos coeficientes de mortalidade perinatal, fetal e neonatal precoce, em todas as categorias. A redução da mortalidade perinatal, nos dez anos, entre os recém nascidos de muito baixo peso $(<1500 \mathrm{~g})$ foi de $35,2 \%$, entre as perdas fetais foi de $22,7 \%$ e igual a $53,8 \%$, entre os óbitos neonatais precoces.

A proporção de baixo peso ao nascer em 2005, em Fortaleza, teve um aumento de quase $23 \%$, em relação à de 1995 , passando de $7,4 \%$ para $9,1 \%$.

Aumento ao redor de $7 \%$ na proporção de baixo peso ao nascer pode ser observado em todas as regiões brasileiras, entre 2000 e 2004. As regiões Sul e Sudeste aumentaram, respectivamente, 6,1\% e 5,8\%; já a região Nordeste apresentou um crescimento de $10 \%{ }^{52}$.

Nos Estados Unidos, a proporção de baixo peso em 2006 foi de 8,3\%, taxa cerca de $9 \%$ menor que a de Fortaleza, em 2005. ${ }^{50}$

Em torno de 18 milhões de crianças nascem com baixo peso ao nascer anualmente em todo mundo, sendo a metade na parte sul do continente asiático. A proporção de baixo peso ao nascer é $14 \%$ em todos os nascimentos e elas contribuem de 60 a $80 \%$ das mortes neonatais. ${ }^{6}$ 
Em Fortaleza no ano de 2005, a proporção de partos cesáreos foi de 39,9\% (12.207), tendo aumentado em relação a 1995, em 30\% (Tabela 16 ).

Outro fato importante é que a maioria dos partos cesáreos em 2005 ocorreu nas instituições privadas conveniadas com o SUS, ficando os hospitais públicos com a maior proporção de partos normais (Tabela)

A Organização Mundial da Saúde estabelece 15\% como limite máximo aceitável para a ocorrência de cesarianas, sendo valores acima considerados "medicamente injustificáveis" (OMS, 1985). A proporção de cesarianas no Brasil vem apresentando valores elevados, tanto para os padrões da OMS, como os de outros países. Em 2006 a proporção de partos cesarianos foi de $45,9 \%,{ }^{52}$

Em todas as regiões brasileiras, o número de partos cesáreos vem crescendo nos últimos anos. As proporções passaram de 32\% em 1994 para 40,2\% em 1996, inclusive sendo uma das maiores taxas de cesarianas do mundo, nesta época. Em 2002 a taxa era de 39,9\%, passando para 42,7\% em 2004, o que representa um aumento de 7,0\% em dois anos. Em 2005, a proporção de cesárea no país era de $44,1 \%$, com aumento de $3,2 \%$ em relação a $2004{ }^{52}$

Vários fatores têm contribuído para este crescente número de cesáreas no Brasil, como a forte resistência dos médicos no que se refere às estratégias para a redução de cesarianas, ambientes desfavoráveis à humanização do parto, número incipiente de enfermeiras obstétricas, assim como, pouca informação acerca dos benefícios do parto normal. Quanto ao setor privado, pode-se acrescer a estes fatores, a inexistência de estratégias 
de incentivo à realização do parto normal pelas operadoras de planos de saúde. ${ }^{56}$

Estudos mostram que a cesariana tem sido adotada, na atualidade, como uma maneira natural e segura de nascer, tanto para a criança, como para a mãe. Ocorrem, em maiores proporções, entre mulheres de alto nível sócio econômico, com maior escolaridade, com baixo risco gestacional e que são atendidas em hospitais privados. ${ }^{55,56,57}$

Proporções tão elevadas são injustificáveis, visto que tanto as indicações supracitadas, assim como as indicações clínicas, não podem justificar estes aumentos. ${ }^{57}$

A proporção de grávidas adolescentes (10 a 19 anos), em 2005, foi de 23\% (7.023), com aumento de aproximadamente 8\% em relação a 1995.

Quanto à evolução da mortalidade perinatal e neonatal precoce em filhos de mães adolescentes, de 1995 a 2005, observaram-se reduções nas duas primeiras na categoria das mães de 10 a 14 anos (respectivamente, $20,6 \%$ e $65,5 \%)$ como nas de 15 a 19 anos $(62,1 \%$ e $51,4 \%$ respectivamente).Quanto ao coeficiente de mortalidade fetal no primeiro grupo foi detectado aumento $(137,3 \%)$ e no segundo redução $(18,9 \%)$. 
Nos países em desenvolvimento, embora o número de gestações entre adolescentes venha decrescendo, ainda se mantém bastante alto quando relacionado aos países ricos. ${ }^{58}$

No Brasil, de acordo com os dados do Ministério da Saúde, a gravidez na adolescência teve uma redução de 22,4\%, no período de 2005 a 2009, e de $34,6 \%$ nos últimos nove anos (2000 a 2009). Essa grande redução ocorreu principalmente na região Nordeste, que obteve um decréscimo de $25 \%$ nos últimos cinco anos. ${ }^{59}$

A maior utilização de preservativos e o maior acesso aos serviços de planejamento familiar são apontados, pelo Ministério da Saúde, como as ações que estão realmente contribuindo para redução da gravidez entre as jovens.

A gravidez na adolescência parece ser maior em regiões menos desenvolvidas e que disponibilizam menos estratégias de saúde pública relacionadas com planejamento familiar tanto nas unidades de saúde como nas escolas e associações de bairro.

Em São Paulo, Porto Alegre e em Recife, em 2005, as proporções de partos entre adolescentes foram iguais a $14,7 \%, 17,6 \%$ e $20,4 \%$. Nos Estados Unidos, essa proporção no mesmo ano foi de $10,2 \%$, sendo maior entre as jovens negras (17,2\%). Em relação aos Estados Unidos, em 2005, a proporção de gestantes adolescentes em Fortaleza foi 2,2 vezes maior. ${ }^{50}$

A evolução observada tanto da gravidez na adolescência, como das mortalidades perinatal, fetal e neonatal precoce, nos dez anos em Fortaleza, pode estar relacionada com a melhor condução do recém nascido/concepto, 
nos hospitais/maternidades de referência, além do melhor manejo da gravidez, trabalho de parto e parto das adolescentes. A garantia de leitos em unidades especializadas nos cuidados com esta clientela especial pode ser uma boa estratégia para a redução de agravos tanto nas gestantes como nos seus recém nascidos. 


\section{CONSIDERAÇÕES FINAIS}

A avaliação dos indicadores da saúde infantil no Ceará, de 1987 a 1994, evidenciava evolução positiva da saúde, que assim estaria graças às ações desenvolvidas da Secretaria de Saúde do Estado e ao envolvimento de vários segmentos da sociedade. Com estas ações foi possível obter queda no componente pós-neonatal do coeficiente de mortalidade infantil, principalmente à custa da diminuição das mortes por diarréia e desnutrição crônica.

O aumento proporcional dos óbitos neonatais, em relação aos tardios, motivou que outras intervenções fossem pensadas. Assim, ações mais específicas e que envolvessem aspectos relacionados com a estrutura, com foco na redução das mortes no primeiro mês de vida e principalmente na primeira semana, eram necessárias.

Após o estudo de 1995, com o diagnóstico da saúde perinatal de Fortaleza, foram adotadas algumas estratégias que envolveram desde a aquisição de recursos materiais, ampliação de leitos de UTI neonatal, insumos até a capacitação de recursos humanos.

Entretanto, como o processo de redução das mortes neonatais é bastante lento, principalmente nos países mais pobres, surgiu a necessidade de novas estratégias na área, com ações destinadas ao controle de fatores de risco para a ocorrência da morbi-mortalidade perinatal. 
A saúde perinatal de Fortaleza em dois momentos, analisada neste estudo em hospitais, por meio de dados epidemiológicos, aponta para a melhora dos indicadores, ao longo dos dez anos, revelando que a assistência e o acesso aos serviços perinatais foram ampliados e de certa forma estão melhores do que em 1995. Entretanto, aspectos relacionados com a estrutura de saúde do município, com o processo de trabalho e com a organização como um todo ainda estão incipientes, principalmente quando comparados com centros mais desenvolvidos do país.

Assim, comparando os dois estudos foi possível constatar:

- redução dos coeficientes de mortalidade hospitalar perinatal, fetal e neonatal precoce para todas as faixas de peso ao nascer, entre 1995 e 2005;

- decréscimo importante alcançado pelo coeficiente de mortalidade neonatal precoce hospitalar;

- queda do coeficiente de mortalidade hospitalar perinatal entre os nascimentos de muito baixo peso $(<1500 \mathrm{~g})$, com ênfase para o neonatal precoce que diminuiu mais da metade, sugerindo um melhor manejo destes nascidos vivos, no âmbito das unidades hospitalares neonatais;

- aumento na proporção de recém nascidos de baixo peso em hospitais de Fortaleza, mostrando haver melhor atenção à gestante, evitando perdas fetais;

- redução das perdas fetais principalmente entre os conceptos hospitalares com peso ao nascer maior ou igual a $2.500 \mathrm{~g}$; 
- redução dos coeficientes de mortalidade perinatal, fetal e neonatal precoce hospitalar entre as grávidas adolescentes.

Ao final desta pesquisa, apesar de alguns ganhos, constata-se que ainda muito precisa ser feito em favor das gestantes, de seus conceptos e dos recém nascidos nos primeiros dias de vida.

Um grande movimento tem motivado a constituição de REDES de Saúde Peri-Neonatal por todo o país. Estas Redes buscam através da utilização de métodos de educação o aumento da base de conhecimentos e mudanças de desempenho pelos profissionais de saúde. ${ }^{40}$

Com a Rede de Saúde Perinatal do Norte e Nordeste, muitas estratégias têm sido discutidas, em favor da melhoria dos cuidados prestados aos recém nascidos em UTI neonatal em todos os estados dessas regiões. Por meio das consultorias clínicas in loco, onde são discutidos protocolos e condutas com médicos e enfermeiras, as principais dificuldades sentidas pelos profissionais são conhecidas. Já é possível constatar que, em muitas unidades neonatais, não há compreensão da relação entre qualidade e educação permanente.

Não é mais possível admitir o desconhecimento de que as mortes perinatais são passíveis de redução, com mecanismos e instrumentos já disponíveis e utilizados. Portanto, é imperiosa a adoção de novas estratégias, centradas na atenção obstétrica e neonatal. Para tanto, é necessário mostrar, por meio de achados epidemiológicos, quantas destas mortes foram desnecessárias por que deveriam ter sido evitadas. 


\section{REFERÊNCIAS BIBLIOGRÁFICAS}

1. Fundo das Nações Unidas Para a Infância. Situação Mundial da Infância, 2008.

2. Oliveira LAP, Mendes MMS. Mortalidade infantil no Brasil: uma avaliação de tendências recentes.In: Minayo, M.C.S.(org.).Os muitos Brasis:saúde e população na década de 80. São Paulo: Hucitec, 1995.p. 291-303.

3. Leal MC. \&Szwarcwald CL. Evolução da mortalidade neonatal no Estado do Rio de Janeiro, Brasil, de 1979 a 1993. 1 - Análise por grupo etário segundo região de residência. Rev. Saúde Pública, 30 (5): 403-12, 1996.

4. Ca Tome. Determinantes das diferenças de mortalidade infantil entre as etnias da Guine-Bissau, 1990-1995. 1999. 91f. Dissertação (Mestrado em Saúde Coletiva) Fundação Oswaldo Cruz, Escola Nacional de Saúde Pública, Rio de Janeiro

5. Barros FC. \&Victora CG. Saúde Materno-Infantil em Pelotas, Rio Grande de Sul, Brasil, 1982-1993: uma década de transição. Cad. Saúde Pública, v. 12, 1996. Supl. 1.

6. LawnJE.,Cousens S., Zupan J.Lancet Neonatal Survival Steering Team. 4 million neonatal deaths: when? where?why? Lancet. 2005; 365(9462): 891900.

7. Jones G., Steketee RW, Black, RE., Bhutta ZA., Morris, SS. Bellagio Child Survival Study Group. How many deaths can we prevent this year? Lancet. 2003;362 (377): 65-71.

8. Leite AJM. Mortalidade perinatal e aspectos da qualidade da atenção à saúde no município de Fortaleza-1995. 1996. Dissertação (Mestrado em 
Epidemiologia) - Escola Paulista de Medicina, Universidade Federal de São Paulo, São Paulo.

9. Simões CCS. \& Monteiro CA. Tendência secular e diferenças regionais da mortalidade infantil no Brasil. In: Monteiro,CA (org) - Velhos e novos males da saúde no Brasil: a evolução do país e de suas doenças. São Paulo, HUCITEC, 1995. p 153-56.

10. Mosley WH. \& Chen LC. - An analytical framework for the study of child survival in developing countries.Populat. Develop. Rev., 10(suppl.): 25-

45,1984 .

11. Duarte JLMB. \& Mendonça GAS. Fatores associados à morte neonatal em recém nascidos de muito baixo peso ao nascer em quatro maternidades no município do Rio de Janeiro. Brasil. Cad. Saúde Pública.2005; 21(1): 181-191.

12. Silva AC. Viva Criança: os caminhos da sobrevivência infantil no Ceará. Fortaleza: Edições Fundação Demócrito Rocha, 1999.

13. Caldwell,JC. Education as factor in mortality decline. An examination of Nigerian data, in meeting on socioeconomics determinants and consequences of mortality.México.1979.WHO.

14. Ortiz Flores LP. Características da mortalidade neonatal no Estado de São Paulo [Tese de Doutorado]. São Paulo: Faculdade de Saúde Pública, Universidade de São Paulo; 1999.

15. Starfield BC., CassadyJ., Nanda CB.,and Forest RB. 1998. Consumer experiences and providerperceptions of the quality of primary care: implications for managed care. Journal of Family Practice46:216226. 
16. Musgrove P. Relaciones entre la salud y el desarrollo. Bol. OfSanit. Panam., 142(2): 115-29. 1993

17. Szwarcwald CL., Leal MC.,Castilho EA.,Andrade CLT., Mortalidade infantil no Brasil:Belíndia ou Bulgária? Cad. Saúde Públ., Rio de Janeiro, 13(3):503-516, jul-set, 1997.

18. Amaral J, Gouws E, Bryce J, Leite AJM, Cunha ALA, Victora CG. Effect of integrated management of childhood illness $(\mathrm{IMCl})$ on health worker performance in Northeast-Brazil.Cad. Saúde Pública 2004; 20 (Sup2):S209S219.

19. Monteiro CA, Benicio MHD'A, Freitas ICM. Melhoria em indicadores de saúde associados à pobreza no Brasil dos anos 90: descrição, causas e impacto sobre desigualdades regionais. São Paulo: NUPENS/USP; 1997.

20. Victora CG, Barros FC \&Vaughan J P. Epidemiologia da Desigualdade. 3ª edição.São Paulo:HUCITEC;2006

21. OrganizacionPanamericana de La Salud. Centro Latino Americano de Perinatologia e Desenvolvimento Humano - Saúde Perinatal: artigos selecionados de La saludperinatal.Boletim do CLAP. Montevidéu, 1988.17p.

22. Leal MC., Gama SGN., Cavalini LT., Garbayo LS., Campos R., Somberg M DC. \& Brasil CP. Estudo da morbi-mortalidade e da atenção peri e neonatal no Município do Rio de Janeiro, 1999. In: Congresso Brasileiro de Saúde Coletiva, Resumos, p. 378. Salvador: Associação Brasileira de PósGraduação em Saúde Coletiva;2000 
23. Pedrosa LDCO.,Sarinho SW.,andOrdonha MAR. Óbitos neonatais: por que e como informar?.Rev. Bras. Saude Mater. Infant. [online]. 2005, vol.5, n.4, pp. 411-418.

24. Laurenti R. Perinatal health.Rev. Saúde Pública. São Paulo, v. 18, n. 4 , 1984.

25.Bobadilla JL. Los efectos de lacalidad de laatencion medica em lasobrevivência perinatal. Salud Publica Mexico 1988; 30: 416-31.

26. Schawarcz R., Diaz AG.Algunos problemas associados a la mortalidade maternal y perinatal em las Américas. In: CLAP. Tecnologias Perinatales Montevideo, 1992 p 7-29.

27.Leal MC.Perinatalidade no Rio de Janeiro.Cad. Saúde Pública v.20 supl.1 Rio de Janeiro 2004.

28.Fonseca SC., Coutinho ESF. Pesquisa sobre a mortalidade Perinatal no Brasil: revisão da metodologia e dos resultados. Cad. Saúde Pública, 2004: 20 sup1:S7-S19.

29. Andrade CLT, Szwarcwald CL, Gama SGN, Leal M.C. Desigualdadessócioeconômicas do baixo peso ao nascer e damortalidade perinatal no município do Rio de Janeiro, 2001.Cad Saúde Pública 2004;20(Supl. 1):S44-S51.23 Goldani MZ, Barbieri MA, Bettiol H, Barbieri MR, Tomkins

30. Morais Neto OL., Barros MBA. Fatores de risco para mortalidade neonatal e pós-neonatal na Região Centro-Oeste do Brasil: linkage entre bancos de dados de nascidos vivos e óbitos infantis.Cad. Saúde Pública., Rio de Janeiro, v. 16, n. 2, 2000. 
31. Mcauliffe J., Lima LC., Granjeiro GP. - III Pesquisa de saúde materno-infantil do Ceará/1994 - PESMIC 3. Fortaleza, SESA, 1995. 61p

32. Victora CG., Barros FC. Infant Mortality due to perinatal causes in Brazil.Trends, regional patterns and possible interventions. Rev Paul Med, $200111933-42$.

33. Bezerra FJG, Kerr LRFS, Miná DL, Barreto ML. Distribuição espacial da taxa de mortalidade infantil e principais determinantes no Ceará, Brasil, no período 2000-2002. Cad. Saúde Pública .2007 May :23(5).

34. Ministério da Saúde (BR). DATASUS. Informações de Saúde. Nascidos vivos.Disponível:http://tabnet.datasus.gov.br/cgi/tabcgi.exe?sinasc/cnv/nvuf.de f.

35. Leite AJM, Marcopito LF, Diniz RLP, Silva AVS, Souza LCB, Borges JC, SáHLC. Mortes perinatais no Município de Fortaleza, Ceará: o quanto é possívelevitar? J Pediatr 1997; 73: 388-94.

36.Secretaria Municipal Saúde de Fortaleza. Célula de Vigilância Epidemiológica. Dados de nascidos vivos e mortalidade infantil em Fortaleza.

37. Morais Neto, OL. Barros MBA. Fatores de risco para mortalidade neonatal e pós-neonatal na Região Centro-Oeste do Brasil: linkage entre bancos de dados de nascidos vivos e óbitos infantis.Cad. Saúde Pública., Rio de Janeiro, v. 16, n. 2, 2000.

38. Gama SGN.,Szwarcwald CL. \& Leal MC. Experiência de gravidez na adolescência, fatores associados e resultados perinatais. Cad. Saúde Pública, Rio de Janeiro, 18(1):153-161, jan-fev, 2002. 
39. Costa JO., Xavier CC., Proietti FA., Delgado MS. Avaliação dos recursos hospitalares para assistência perinatal em Belo Horizonte, Minas Gerais. Rev. Saúde Pública :2004, 38(5): 701-708.

40. Leite AJM. \& Almeida NMG.Mortalidade Peri neonatal: situação atual e perspectivas futuras. Artmed: PRÓ-RN, modulo 4, ciclo 5, 2009.

41. Castro ECM. \&Leite AJM.Hospital mortality rates of infants with birth weight less than or equal to $1,500 \mathrm{~g}$ in the northeast of Brazil.Jornal de Pediatria, 2007, Vol. 83, №1.

42.Lansky S., \&, Leal MC.Mortalidade perinatale evitabilidade: revisão de literatura Horizonte, Minas Gerais, Brasil, 1999. Cad. de Saúde Pública, 2002; $18: 1389-400$.

43. Menezes AMB., Barros FC., Victora CG., Tomasi E., Halpern R., Oliveira ALB. Fatores de risco para mortalidade perinatal em Pelotas,RS , 1993. Rev. Saúde Pública 1998; 32 (3) : 209-16.

44. Camargo ABM. A natimortalidade e a mortalidade perinatal em São PauloSão Paulo em Perspectiva, v. 22, n. 1, p. 30-47, jan./jun. 2008

45.Sobieray NLEC. Estudo da mortalidade perinatal do município de Curitiba no Período de 2002 A 2005.2009. Dissertação (Mestrado em Medicina Interna e Ciências da Saúde) - Universidade Federal do Paraná, Paraná

46.Leal MC., Gama SGN.,Campos MR.,Cavalini LT., GarbayoLS.,Brasil CL.,Szwarcwald CL. Fatores associados à morbi-mortalidade perinatal em uma amostra de maternidades públicas e privadas do Município do Rio de Janeiro, 1999-2001. Cad. Saúde Pública, Rio de Janeiro, 20 Sup1:S20-S33, 2004. 
47.Lansky S., França E., Leal MC., Mortes perinatais evitáveis em Belo Horizonte, Minas Gerais, Brasil, 1999. Cad. de Saúde Pública, 2002; 18:1389 - 400.

48. Costa GN.,Mortalidade perinatal, determinantes biológicos, de atençãoà saúde materno infantil e socioeconômicos: uma análise das desigualdades entre os bairros do Recife . 2008.156 Tese (Doutorado em Saúde Pública) FIOCRUZ.

49. Organização Mundial da Saúde. Neonatal and Perinatal Mortality - Country estimates for the year 2000. Department of Measurement and Health.Information Systems (MHI), 2004.

50.Martin JA., Hamilton BE., Ventura SJ., Menacker F., Park MM.Infant mortality and low birth weight among black and white infants UnitedStates,1980-2000. Natl Vital Stat Rep 2002; 50; 1-102.

51.Cartlidge PHT; Stewart JH.Effect of changing the stillbirth definition on evaluation of perinatal mortality rates.Lancet 1995;346(19): 486-8.

52.Organização Panamericana de Saúde. RIPSA. Indicadores de Saúde no Brasil: conceitos e aplicações.2.ed. Brasil. 2008.

53. Menezes, AMB; Barros, FC; Victora, CG; Tomasi, E; Halpern R; Oliveira, ALB. Fatores de risco para mortalidade perinatal em Pelotas, RS, 1993. Rev. Saúde Pública 1998; 32 (3) : 209-16. 
54. Almeida MFB., Guinsburg R., Martinez FE., Procianoy RS., Leone CR., Marba ST., Martins et al . Fatores perinatais associados ao óbito precoce em prematuros nascidos nos centros da Rede Brasileira de Pesquisas Neonatais. J. Pediatr.2008.Rio Janeiro. Aug. 84(4): 300-307.

55.Yazlle MEHD., Rocha JSYR.,Mendes MC.,Patta MC.,Marcolin AC.,Azevedo GD.Incidência de cesáreas segundo fonte definanciamento da assistência ao parto. Rev Saúde Pública 2001;35(2):202-206.

56.Torres JÁ.,A Redução do Parto Cesáreo: O papel do SUS e da saúde suplementar. Agência Nacional de Saúde Suplementar. CONASEMS,Belém, 2008.

57. Silveira DS, Santos IS. Fatores associados à cesariana entre mulheres de baixa renda em Pelotas, Rio Grande do Sul, Brasil. Cad Saúde Pública. 2004; 20: $231-41$.

58. Sakae TM., Freitas PF., D’Orsi E.Fatores associados as taxasde cesárea em hospitaluniversitário.Rev Saúde Pública 2009;43(3):472-80.

59. Partos na adolescência diminuem $22 \%$ em cinco anos. Folha de São Paulo, São Paulo, 08 mar.2010.Equilíbrio e Saúde. Disponível URL: http://www1.folha.uol.com.br

60.Leite AJM. Tendências e Diferenciais da Saúde Perinatal do Município de Fortaleza -2005. Relatório parcial dos dados da pesquisa para a Fundação Cearense de Apóio ao Desenvolvimento Científico e Tecnológico. 2006. 